\title{
Mineralogia e geoquímica de perfis de solo com Terra Preta Arqueológica de Bom Jesus do Tocantins, sudeste da Amazônia
}

\author{
Any Kelly Terra da SILVA ${ }^{1 a^{*}}$, José Tasso Felix GUIMARÁES², Vanda Porpino LEMOS ${ }^{1 b}$, \\ Marcondes Lima da COSTA ${ }^{\text {1c }}$, Dirse Clara KERN ${ }^{3}$
}

\begin{abstract}
RESUMO
A comparação de dados morfológicos, mineralógicos e químicos de solo com horizontes antrópicos - Terra Preta Arqueológica (TPA) com Argissolos adjacentes permitiu identificar os principais processos responsáveis pela formação da TPA em um sítio arqueológico no Município de Bom Jesus do Tocantins, sudeste do Estado do Pará. A similaridade entre os dados dos horizontes subsuperficiais do solo com TPA e solos adjacentes indica que o horizonte antrópico do solo TPA foi provavelmente desenvolvido a partir de um horizonte similar aos Argissolos adjacentes com posterior transformação pedogenética através da introdução de materiais orgânicos e inorgânicos por antigas colonizaçóes humanas, resultando no espessamento do horizonte superficial e em concentraçôes maiores de $\mathrm{CaO}$ e $\mathrm{P}_{2} \mathrm{O}_{5}$ (teores totais), $\mathrm{Zn}$ (teor traço), $\mathrm{P}$ e $\mathrm{Zn}$ disponível (teores disponíveis), além de $\mathrm{Ca}$ e Mg trocáveis (teores trocáveis) em relaçâo aos Argissolos adjacentes. Além disso, essa intervenção antrópica antiga também provocou modificaçóes no horizonte subsuperficial do Argissolo com TPA, como concentraçóes altas de $\mathrm{P}_{2} \mathrm{O}_{5}$ e principalmente P disponível. O Soil Taxonomy e o Sistema Brasileiro de Classificação de Solos (SiBCS) são adequados para a identificaçáo de solo com horizonte antrópico (p.exe. TPA), uma vez que priorizam nas ordens do solo os principais processos pedogenéticos atuantes na formação do solo, relacionados aos horizontes subsuperficiais, além das transformações pedogenéticas posteriores no horizonte superficial. Contudo, este trabalho recomenda o acréscimo de alguns atributos diagnósticos como quantidade de artefatos cerâmicos e líticos, $\mathrm{P}_{2} \mathrm{O}_{5}, \mathrm{P}$ e Zn disponíveis, $\mathrm{C}$ orgânico, $\mathrm{Ca}^{2+}+\mathrm{Mg}^{2+}$ (teores trocáveis), CTC e índice de saturação por bases no horizonte superficial para o agrupamento e distinção dos diversos tipos de solos antrópicos antigos da Amazônia.
\end{abstract}

PALAVRAS-CHAVE: Mineralogia, Pré-história, Região Amazônica, Pedologia.

\section{Mineralogy and geochemistry of soil profiles with Archeological Black Earth from Bom Jesus do Tocantins, southeastern Amazon}

\begin{abstract}
The comparison of morphological, mineralogical and chemical data of a soil with anthropic horizons - Archeological Black Earth (ABE) and surrounding Argissolos (Typic Kandiudox or Ultisols) allowed the identification of the main process acting on the $\mathrm{ABE}$ formation from the town of Bom Jesus do Tocantins, southeastern Pará State. The similarity between the data in the subsurface horizons of $\mathrm{ABE}$ and surrounding soils indicates that the former was likely developed from Argissolos with later pedogenetic transformation by the input of organic and inorganic materials from ancient human settlements, which resulted in thickness of the surface horizon and higher concentrations of $\mathrm{CaO}$ and $\mathrm{P}_{2} \mathrm{O}_{5}$ (total content), $\mathrm{Zn}$ (trace content), available $\mathrm{P}$ and $\mathrm{Zn}$ (available content), and exchangeable $\mathrm{Ca}$ and $\mathrm{Mg}$ (exchangeable content) compared to surrounding Argissolos. Furthermore, such anthropic disturbance also resulted in changes in the subsurface horizon of Argissolos with ABE, such as high concentrations of $\mathrm{P}_{2} \mathrm{O}_{5}$ and available P. The Soil Taxonomy and Brazilian System of Soil Classification (BSSC) are suitable to identify soils with $\mathrm{ABE}$, as they prioritize at the highest categorical level the main pedogenetic process acting on soil development and formation, related to the subsurface horizons, and later pedogenetic transformations in the surface horizon. However, this study proposes the addition of diagnostic properties such as ceramic and lithic artifacts, $\mathrm{P}_{2} \mathrm{O}_{5}$ and available $\mathrm{P}$ and $\mathrm{Zn}$, organic $\mathrm{C}, \mathrm{Ca}^{2+}+\mathrm{Mg}^{2+}$ (exchangeable content), $\mathrm{CEC}$ and base saturation in the surface horizon to classify and discriminate several kinds of anthropic soils in the Amazon region.
\end{abstract}

KEYWORDS: Mineralogy, Pre-history, Amazon region, Pedology.

Programa de Pós-Graduação em Geologia e Geoquímica, Instituto de Geociências - Universidade Federal do Pará, Av. Augusto Corrêa 01, Guamá, CEP: 66075-900, Belém (PA), Brasil. E-mail: ${ }^{1 a}$ anyterra@ufpa.br. *Este trabalho foi extraído da dissertação de mestrado da autora. ${ }^{10}$ vplemos@ufpa.br; ${ }^{10} \mathrm{mlc} @ u f p a . b r$

2 Instituto Tecnológico Vale Desenvolvimento Sustentável - ITVDS. Trav. Dr. Moraes 78, 3a andar, Nazaré, Belém (PA), Brasil. E-mail: tassoguimaraes@gmail.com

${ }^{3}$ Museu Paraense Emílio Goeldi - MPEG. Av. Perimetral 1901, Terra Firme, CEP: 66077-530, Belém (PA), Brasil. E-mail: kern@museu-goeldi.br 


\section{INTRODUÇÃO}

Alguns atributos como textura, cor, estrutura, composição química e mineralógica, capacidade de troca catiônica (CTC) e índice de saturação por bases $(\mathrm{V})$, são largamente utilizados para a distinção e subdivisão das classes de solos. Por exemplo, solos muito profundos, constituídos por material mineral com horizonte subsuperficial B latossólico e pobres em nutrientes são atributos dos Latossolos, enquanto que horizonte subsuperficial B textural com atividade da fração argila baixa $\left(\leq 27 \mathrm{cmol} \mathrm{kg}^{-1}\right)$ ou alta $\left(\geq 27 \mathrm{cmol} \mathrm{kg}^{-1}\right)$ combinada com $\mathrm{V} \geq$ $50 \%$ ou caráter alítico é típico dos Argissolos. O horizonte $\mathrm{B}$ textural encontra-se imediatamente abaixo de qualquer tipo de horizonte superficial, exceto o hístico, sem apresentar os requisitos estabelecidos para serem enquadrados nas classes dos Luvissolos, Planossolos, Plantissolos ou Gleissolos (Embrapa 2006). Estas classes de solo abrangem grande parte da região Amazônica (Lima 2001). Entretanto, algumas áreas apresentam solos com grandes alteraçóes nas características primárias do solo em razão da colonização humana antiga (Pabst 1991). Os horizontes superficiais dos solos destas áreas apresentam coloração escura, restos de material arqueológico (artefatos cerâmicos e líticos) e alta concentração de Ca, $\mathrm{Mg}$, Zn, Mn, P e C orgânico. Smith (1980), Eden et al. (1984) e Kern e Kämpf (1989) definiram estes solos como Terra Preta Arqueológica (TPA) ou Terra Preta de Índio (TPI). A TPA pode ser encontrada em planícies de inundaçáo (várzea e igapó) e terra firme em áreas que variam de um até centenas de hectares (Kern e Kämpf 2005).

Aspectos texturais e características químicas e mineralógicas de solos dos sítios arqueológicos de Caxiuaná indicam que a TPA foi formada sobre Latossolos Amarelos pré-existentes, nos quais derivaram da alteração de antigos perfis lateríticos. Antes da ocupação humana os solos desses perfis deveriam constituir uma única unidade de solo, mas as atividades desenvolvidas pelos antigos habitantes da regiáo durante longo período de tempo provocaram mudanças nos horizontes superiores desta unidade de solo (Gurjão et al. 2010).

A fertilidade da TPA é geralmente superior às outras classes de solos da Amazônia (p. exe. Kern e Kämpf 1989; Lima et al. 2002). Além disso, diversos estudos têm mostrado que as taxas de mineralização do carbono e as perdas de nutrientes por lixiviação são baixas (p. exe. Lehmann et al. 2003), o que contribui para a preservação natural da TPA. Assim, estes solos são freqüentemente utilizados pelas populaçôes locais para o cultivo de hortaliças, cereais, frutas, mandioca e legumes (Kim et al. 2007).

Os sítios arqueológicos com TPA podem corresponder a horizontes superficiais de várias classes de solos como Latossolos, Argissolos, Cambissolos, Plintossolos e Espodossolos (Kern et al. 2003). Entretanto, Kämpf et al. (2003) consideram as classificaçóes pedológicas tradicionais impróprias para o agrupamento e distinção dos diversos tipos de solos antrópicos uma vez que estas enfatizam os horizontes subsuperficiais que são menos sensíveis a modificaçôes por atividades humanas. A influência da atividade humana (antiga e atual) é definida pelo do horizonte superficial no Sistema Brasileiro de Classificação de Solos - SiBCS (Embrapa 2006) e Soil Taxonomy (Soil Survey Staff 2010). Por exemplo, o solo com TPA pode ser classificado como Latossolo Amarelo distrófico antrópico no SiBCS, onde a influência antrópica é reconhecida a partir dos subgrupos (quarto nível categórico). A Food and Agriculture Organization-World Reference Base For Soil Resources (FAOWRB) agrupa o solo com TPA em Hortic Anthrosols (FAO 2007). Esta classe apresenta solos formados ou profundamente modificados por atividades humanas, como cultivo ou adição de materiais orgânicos (resíduos domésticos). Os solos com TPA da Amazônia podem abranger tipos diferentes de Hortic Anthrosols (Sombroek et al. 2002), mas segundo Kämpf et al. (2003) grande parte é excluída dos Anthrosols em virtude da espessura $\geq 50 \mathrm{~cm}$ requerida para o horizonte superficial. $\mathrm{Na}$ tentativa de classificar o solo com TPA, Sombroek et al. (2002) listaram alguns critérios como espessura da camada escura, textura, concentração de C orgânico, CTC, V, P disponível (extrator de Mehlich-1), Mn e Zn disponível.

As características químicas do solo, efetivamente empregadas na classificação do solo com TPA, têm sido intensamente estudadas na região de confluência entre os rios Amazonas, Negro e Solimóes (p.exe. Kern e Costa 1997; Major et al., 2005), mas informaçóes sobre solos com TPA na regiấo dos rios Araguaia e Tocantins ainda são muitos escassas. No Município de Bom Jesus do Tocantins ocorrem Argissolos com a presença de horizontes antrópicos. Portanto, o objetivo deste trabalho é caracterizar o comportamento geoquímico dos solos com TPA e Argissolos adjacentes e os principais processos responsáveis pela formação da TPA por meio de características morfológicas, composiçáo mineralógica e química dos perfis de solo de um sítio arqueológico no Município de Bom Jesus do Tocantins, sudeste do Estado do Pará. Além disso, este estudo interdisciplinar pode contribuir para o aperfeiçoamento dos sistemas de classificação de solos com horizontes superficiais antropicamente modificados.

\section{MATERIAL E MÉTODOS}

\section{Área de estudo}

A área de estudo está localizada no município de Bom Jesus do Tocantins. Esta região apresenta relevo caracterizado por áreas acidentadas, dissecadas, tabuliformes, colinosas com rebordos erosivos, superfícies aplainadas, serras de pequena extensão e várzeas, que estão inseridas nas unidades morfoestruturais da Depressão Periférica do Sul do Pará e do Planalto Setentrional Pará-Maranhão (Sepof 2008). A drenagem da região faz parte da bacia hidrográfica Araguaia- 
Tocantins que abrange a bacia do Rio Tocantins, Araguaia e Itacaiunas. A rede de drenagem deste município apresenta uma densidade baixa a moderada, padrão do tipo dentrítico e principais tributários com sentido NE-SW. Os tributários mais importantes são os Rios Flexeira, Mãe Maria, Jacundá, Jacundazinho, Boa Sorte, Cajueiro e Grapiá. Os tipos de solos do município de Bom Jesus do Tocantins podem ser classificados como Latossolos Amarelos, Argissolos VermelhoAmarelos, Argissolos Amarelos e Gleissolos Háplico (Sepof 2008). As unidades de vegetação são a Floresta Ombrófila Densa Submontana, principalmente representada pela Manilkara huberi Ducke (Sapotaceae), Bertholletia excelsa H.B.K (Lecythidaceae) e Hymenolobium petraeum Ducke (Fabaceae), Floresta Ombrófila densa aluvial que ocorre em planícies de inundação e possui espécies como Carapa guianensis Aublet. (Meliaceae), Protium tenuifolium Engl. (Burseraceae) e Hura crepitans L. (Euphorbiaceae), e coberturas antrópicas (Figura 1a). O clima é equatorial superúmido, tipo Am-Aw na classificação de Köppen, com temperaturas e umidade relativa médias anuais de $26^{\circ} \mathrm{C} \mathrm{e} 78 \%$ respectivamente. $\mathrm{O}$ período chuvoso ocorre entre os meses de novembro e maio, e o período seco nos meses de junho a

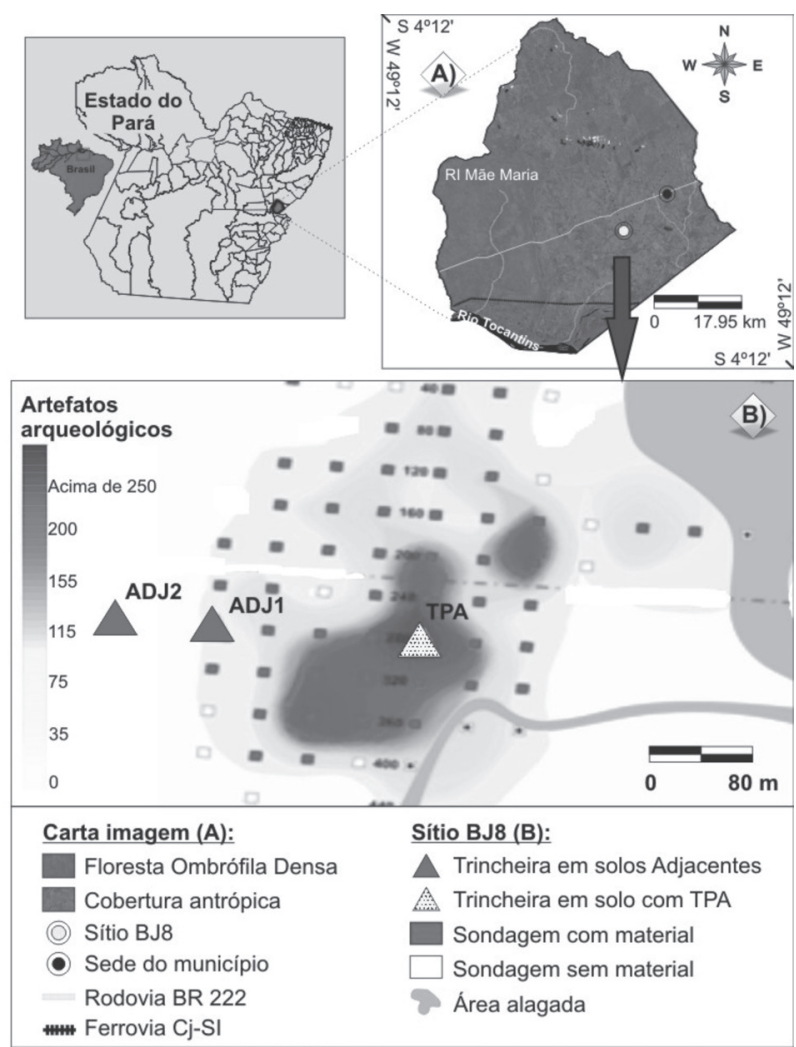

Figura 1- A) Composição: Landsat/TM-5R4G3B com a delimitação das áreas vegetadas e alteradas e B) sítio arqueológico BJ8 com pontos de amostragem no Município de Bom Jesus do Tocantins-PA. novembro, com índice pluviométrico médio anual em torno de 2,000 mm (Fisch et al. 1998).

\section{Amostragem e procedimentos laboratoriais}

As amostras de solo analisadas neste estudo foram obtidas em um sítio arqueológico (BJ8; $05^{\circ} 06^{\prime} 42^{\prime \prime} \mathrm{S}, 48^{\circ} 40^{\prime} 27^{\prime \prime}$ W) que compreende um perfil de Argissolo com horizonte A antrópico (TPA), e dois perfis adjacentes de Argissolos a 160 m (ADJ1) e 280 m (ADJ2) de distância, respectivamente. No trabalho de delimitaçáo, a área de ocorrência foi vistoriada e limpa, e posteriormente selecionada a área de maior abundância de artefatos, na qual foram abertas trincheiras em malha ortogonal com espaçamento regular de $40 \mathrm{~m}$ (Figura 1b). As trincheiras foram abertas até atingir o horizonte B ( $1,5 \mathrm{~m})$, e 19 amostras de solo foram coletadas dos horizontes descritos (A, AB, BA e B). Em cada perfil de solo foram descritos a textura, estrutura, cor, profundidade, consistência e presença de raízes segundo a metodologia de Lemos e Santos (2002). Amostras com material arqueológico foram peneiradas, e os fragmentos $(\leq 20 \mathrm{~cm})$ analisados com uma lupa portátil conforme recomendaçóes de Kämpf et al. (2003).

As amostras de solos de cada horizonte foram secas ao ar e posteriormente destorroadas e homogeneizadas. Em seguida, foi separada uma alíquota de $50 \mathrm{~g}$ para análise granulométrica (Soil Survey Staff 1993). Uma adaptação do método da pipeta de Kilmer e Alexander (1949) foi aplicada para análise do tamanho das partículas conforme as recomendaçóes do USDA (Soil Survey Staff 1993). Para as análises mineralógicas e químicas, as amostras foram desagregadas, trituradas e pulverizadas $(<0,0625 \mathrm{~mm})$ e para análise de fertilidade foram desagregadas e passadas em peneira com malha $<2$ $\mathrm{mm}$ obtendo a terra fina seca ao ar (TFSA).

As análises mineralógicas foram realizadas por difração de raios-X (DRX) através do PANalytical diffractometer model $\mathrm{PW}$ 3040 , com anodo de cobre $(\mathrm{k} \alpha 1=0,154 \mathrm{~nm})$, ajustado a 40 $\mathrm{kV}$ e $30 \mathrm{~mA}$. As amostras foram analisadas pelo método do pó e em lâminas orientadas pelo pipette-on-glass (Thorez 1976) para os argilominerais. Três tipos de lâminas foram preparadas: normal, saturada com etilenoglicol e sob aquecimento a 550 ${ }^{\circ} \mathrm{C}$ por 2 horas. Os registros foram obtidos no intervalo de 5 a $75 \circ 2 \theta$ para as amostras totais pulverizadas e no intervalo 3 a $36 \circ 2 \theta$ para os argilominerais. Os resultados foram interpretados com auxílio do software X'Pert HighScore 2.1 com banco de dados do ICDD (International Center for Diffraction Data) e apresentados como símbolos segundo Kretz (1983).

As análises químicas foram realizadas nas amostras de solo com $\varnothing<2 \mathrm{~mm}$ por Espectrometria de Emissão Óptica com Plasma Aclopado Indutivamente (ICP-OES) na sequência de uma fusão metaborato/tetraborato de lítio e digestão em ácido nítrico diluído no laboratório da SGS 
GEOSOL, Complexometria, Colorimetria e Espectrometria de Absorção Atômica (EAA) no Laboratório de Análises Químicas e Absorção Atômica no Instituto de Geociências da Universidade Federal do Pará (Tabela 1). P, K e Na trocáveis foram obtidos através do extrator de Mehlich-1 e colorimetria, Ca e $\mathrm{Mg}$ trocáveis pelo extrator $\mathrm{KCl} 1 \mathrm{~mol} \mathrm{~L}^{-1}$ e EAA. A carga líquida do solo $(\Delta \mathrm{pH})$ foi estimada pela Potenciometria através da diferença entre $\mathrm{pH}_{\mathrm{H} 2 \mathrm{O}}$ e $\mathrm{pH}_{\mathrm{KCl}}$ A partir do $\mathrm{K}, \mathrm{Na}$, Ca e $\mathrm{Mg}$ trocáveis e acidez potencial $(\mathrm{Al}+\mathrm{H})$ foram obtidos a soma de bases trocáveis $(\mathrm{SB})$, capacidade de troca catiônica (CTC) e índice de saturação por bases (V). O C orgânico foi analisado através do Walkley-Black (Walkley e Black 1934). Cálculos estequiométricos foram realizados para semi-quantificar a distribuição dos minerais identificados por DRX.

Os solos foram classificados de acordo com o Sistema Brasileiro de Classificação de Solo (Embrapa 2006), Soil Taxonomy (Soil Survey Staff 2010), FAO-WRB (FAO 2007) e Archaeo-pedological Classification - APC (Kämpf et al. 2003).

As concentraçóes dos elementos maiores e traços foram normalizados com a Crosta Continental Superior - UCC (Wedepohl 1995) e folhelhos australianos Pós-Arqueanos - PAAS (Taylor e MacLennan 1985). Adicionalmente, as concentraçôes dos solos TPA foram normalizadas com os solos adjacentes. A análise estatística do grau de similaridade dos dados, para avaliação das associaçōes geoquímicas associadas à Argissolos com e sem horizonte antrópico, foi realizada por meio do método da ligaçáo simples (Single Linkage) e correlação $\rho$ de Pearson (coeficiente produto-momento).

\section{RESULTADOS E DISCUSSÃO}

\section{Características morfológicas}

A análise granulométrica do solo TPA indicou a predominância da fração areia sobre as fraçôes mais finas (silte e argila), e uma diminuição relativa destas do horizonte subsuperficial para o superficial (Tabela 2). O horizonte subsuperficial $(73-150 \mathrm{~cm})$ é composto por areia $(648-760$ $\left.\mathrm{g} \mathrm{kg}^{-1}\right)$, silte (135-193 $\left.\mathrm{g} \mathrm{kg}^{-1}\right)$ e argila (105-167 $\left.\mathrm{g} \mathrm{kg}^{-1}\right)$, textura franco-arenosa, bruno-forte (7.5YR 5/6) a bruno (7.5YR 4/4), blocos subangulares a granular, friável a firme, enquanto o horizonte superficial $(73-0 \mathrm{~cm})$ é constituído por areia $\left(765-885 \mathrm{~g} \mathrm{~kg}^{-1}\right)$, silte $\left(96-138 \mathrm{~g} \mathrm{~kg}^{-1}\right)$ e argila (18$\left.97 \mathrm{~g} \mathrm{~kg}^{-1}\right)$, textura classificada como areia a franco-arenosa, bruno-acinzentado muito escuro (10YR 3/2) a preto (10YR $2 / 1$ ), blocos subangulares a granular, friável (Tabela 2). No sítio como um todo, foram catalogados 1920 fragmentos cerâmicos e líticos, raízes, marcas de raízes, folhas e outros materiais vegetais.

Os solos adjacentes são representados basicamente pela fração areia, mas os teores de silte e argila são maiores que o perfil do solo TPA (Tabela 2). A quantidade da fraçáo fina também diminui do horizonte subsuperficial para o superficial. O horizonte subsuperficial $(25-150 \mathrm{~cm})$, mais espesso que o horizonte correspondente no solo TPA, contém areia (501-638 $\left.\mathrm{g} \mathrm{kg}^{-1}\right)$, silte $\left(222-344 \mathrm{~g} \mathrm{~kg}^{-1}\right)$ e argila $\left(80-223 \mathrm{~g} \mathrm{~kg}^{-1}\right)$, textura franco argilo-arenosa a franco-arenosa, bruno-forte (7.5YR 4/6) a marrom escuro (7.5YR 3/4), blocos subangulares a granular, friável a firme. A espessura do horizonte superficial $(0-25 \mathrm{~cm})$ é menor que o horizonte correspondente no solo TPA, e contém areia (557-709 $\left.\mathrm{g} \mathrm{kg}^{-1}\right)$, silte (239-380 $\left.\mathrm{g} \mathrm{kg}^{-1}\right)$ e argila (52-67 $\left.\mathrm{g} \mathrm{kg}^{-1}\right)$, textura franco-arenosa, bruno-escuro (7.5YR 3/3) a bruno-acinzentado muito escuro (10YR 3/2), blocos subangulares a granular, friável, muitas raízes finas a médias e folhas (Tabela 2). A análise granulométrica das amostras de solo pode indicar um processo de argiluviaçáo que ocorre nos perfis estudados.

\section{Características mineralógicas}

Os minerais identificados no perfil de solo com TPA foram o quartzo, caulinita, goethita, hematita, anatásio e illita, equivalente à mineralogia encontrada em outros solos com TPA na região de Caxiuanã (Lemos et al. 2009). A albita não faz parte da composiçáo dos solos, porém foi encontrada no horizonte $\mathrm{A}$, oriunda dos artefatos cerâmicos que sáo abundantes neste horizonte (Figura 1b). Os difratogramas obtidos na fração argila pelo método pipette-on-glass reforçam a presença de illita e caulinita no solo e os picos mais desenvolvidos de caulinita ocorrem no horizonte B (Figura 2). Quartzo, caulinita e anatásio são provavelmente derivados do intemperismo de rochas do Grupo Itapecuru (Nascimento e Góes 2007), sobreposto pelos solos analisados neste trabalho. Hematita e goethita podem ser originárias da oxidação de argilominerais durante os processos pedogenéticos. Os dados semi-quantitativos obtidos por cálculos estequiométricos revelam que os maiores valores de quartzo estáo no horizonte A, enquanto que a caulinita está concentrada no horizonte B.

Tabela 1- Procedimentos de análises químicas e de fertilidade empregados nas amostras de solo.

\begin{tabular}{|c|c|}
\hline Parâmetros & Métodos Analíticos \\
\hline Perda ao Fogo, $\mathrm{SiO}_{2}$ & Gravimetria e ICP-OES \\
\hline $\mathrm{Fe}_{2} \mathrm{O}_{3}, \mathrm{TiO}_{2}, \mathrm{P}_{2} \mathrm{O}_{5}$ & Colorimetria e ICP-OES \\
\hline $\mathrm{CaO}, \mathrm{Na}_{2} \mathrm{O}, \mathrm{MgO}, \mathrm{K}_{2} \mathrm{O}$ & $\begin{array}{c}\text { Digestão Total } \mathrm{HClO}_{4}+\mathrm{HF} \text {, EAA e } \\
\text { ICP-OES }\end{array}$ \\
\hline $\mathrm{Al}_{2} \mathrm{O}_{3}$ & Complexometria com EDTA e ICP-OES \\
\hline Carbono Orgânico (CO) & Walkley-Black \\
\hline $\begin{array}{c}\mathrm{Ba}, \mathrm{Sr}, \mathrm{Sc}, \mathrm{Y}, \mathrm{Zr}, \mathrm{V}, \mathrm{Be}, \mathrm{Cr}, \mathrm{Ni}, \mathrm{Co}, \\
\mathrm{Cu}, \mathrm{Zn}, \mathrm{Pb}\end{array}$ & $\begin{array}{l}\text { Digestão Total HF }+\mathrm{HClO}_{4} \text {, EAA e } \\
\text { ICP-OES }\end{array}$ \\
\hline $\mathrm{P}, \mathrm{Zn}, \mathrm{Fe}, \mathrm{Mn}, \mathrm{Cu}$ & Extrator de Mehlich-1 e EAA \\
\hline P disponível & Extrator de Mehlich-1 e colorimetria \\
\hline $\mathrm{Ca}^{2+}$ e $\mathrm{Mg}^{2+}$ trocáveis & Extrator $\mathrm{KCl} 1 \mathrm{~N}$ e EAA \\
\hline $\mathrm{K}^{+}$e $\mathrm{Na}^{+}$trocáveis & Extrator de Mehlich-1 e EAA \\
\hline $\mathrm{pH}-\mathrm{KCl} 1 \mathrm{~N}, \mathrm{pH}-\mathrm{H}_{2} \mathrm{O}$ & 1:2,5 - Potenciômetro \\
\hline
\end{tabular}


Tabela 2- Descrição morfológica dos solos do sítio BJ8.

\begin{tabular}{|c|c|c|c|c|c|c|c|c|c|}
\hline \multirow{2}{*}{ Horiz. } & \multirow{2}{*}{$\begin{array}{l}\text { Prof. } \\
(\mathrm{cm})\end{array}$} & \multirow{2}{*}{ Cor } & \multirow{2}{*}{$\begin{array}{l}\text { Estrutura } \\
\text { (1) }\end{array}$} & \multirow{2}{*}{ Consistência (2) } & \multirow{2}{*}{$\begin{array}{c}\text { Transição (3) } \\
\text { Areia }\end{array}$} & \multicolumn{3}{|c|}{ Granulometria $\mathrm{g} \mathrm{kg}^{-1}$} & \multirow{2}{*}{$\begin{array}{l}\text { Textura } \\
\text { (4) }\end{array}$} \\
\hline & & & & & & Silte & Argila & & \\
\hline \multicolumn{10}{|c|}{ Solo com TPA } \\
\hline $\mathrm{A} 1$ & $0-3$ & 10YR 2/1 & fc, gr & $\mathrm{mf}$ & $\mathrm{gl}, \mathrm{pn}$ & 885 & 96 & 18,4 & $A$ \\
\hline $\mathrm{A} 2$ & $3-33$ & 10YR 2/1 & fc, gr & mf, npl, npj & gl, pn & 859 & 116 & 25,2 & $\mathrm{AF}$ \\
\hline A3 & $33-42$ & 10YR 3/2 & fc, gr & mf, npl, npj & $\mathrm{gl}, \mathrm{pn}$ & 824 & 126 & 50,0 & $\mathrm{AF}$ \\
\hline$A B$ & $42-73$ & 10YR 3/2 & $\begin{array}{l}\text { mod, } \mathrm{pq} / \mathrm{gd}, \mathrm{bsa} / \\
\mathrm{gr} / \mathrm{gs}\end{array}$ & f, Ipl, Ipj & gl, pn & 765 & 138 & 97,0 & FA \\
\hline BA & 73- 88 & 7.5YR 4/4 & $\begin{array}{l}\mathrm{mod}, \mathrm{pq} / \mathrm{gd}, \mathrm{bsa} / \\
\mathrm{gr} / \mathrm{gs}\end{array}$ & $\mathrm{f}, \mathrm{pl}, \mathrm{Ipj}$ & gl, pn & 760 & 135 & 105 & $\mathrm{FA}$ \\
\hline B1 & $88-110$ & 7.5YR 4/6 & $\begin{array}{l}\text { mod, } \mathrm{pq} / \mathrm{gd}, \mathrm{bsa} / \\
\mathrm{gr} / \mathrm{gs}\end{array}$ & $\mathrm{f}, \mathrm{pl}, \mathrm{pj}$ & $\mathrm{df}, \mathrm{pn}$ & 715 & 161 & 124 & FA \\
\hline B2 & $110-150$ & 7.5YR 5/6 & $\mathrm{ft}, \mathrm{pq} / \mathrm{gd}, \mathrm{bsa} / \mathrm{gr}$ & $\mathrm{fm}, \mathrm{pl}, \mathrm{mpj}$ & - & 640 & 193 & 167 & FA \\
\hline \multicolumn{10}{|c|}{ ADJ1 } \\
\hline $\mathrm{A} 1$ & $0-11$ & 10YR 3/2 & gr & mf, Ipl, pj & $\mathrm{cl}, \mathrm{pn}$ & 709 & 239 & 52 & FA \\
\hline$A B$ & $11-25$ & 10YR $3 / 4$ & fc, $\mathrm{pq} / \mathrm{med}, \mathrm{bsa} / \mathrm{gr}$ & $\mathrm{mf}, \mathrm{Ipl}, \mathrm{pj}$ & $\mathrm{cl}, \mathrm{pn}$ & 645 & 288 & 67 & FA \\
\hline $\mathrm{BA}$ & $25-40$ & 10YR $3 / 4$ & fc, pq/med, bsa/gr & $\mathrm{f}, \mathrm{pl}, \mathrm{pj}$ & $\mathrm{gl}, \mathrm{pn}$ & 576 & 344 & 80 & $\mathrm{FA}$ \\
\hline B1 & $40-74$ & $7.5 Y R 4 / 4$ & $\mathrm{pq} / \mathrm{gd}, \mathrm{bsa} / \mathrm{gr}$ & $\mathrm{f}, \mathrm{Ipl}, \mathrm{pj}$ & $\mathrm{gl}, \mathrm{pn}$ & 638 & 222 & 140 & FA \\
\hline B2 & $74-95$ & $7.5 Y R \quad 4 / 6$ & mod, pq/gd, bsa/gr & fm, npl, npj & $g l, p n$ & 561 & 259 & 180 & FA \\
\hline B3 & $95-150$ & 7.5YR 4/6 & mod, pq/gd, bsa/gr & $\mathrm{fm}, \mathrm{npl}, \mathrm{npj}$ & gl, pn & 560 & 250 & 190 & FA \\
\hline \multicolumn{10}{|c|}{ ADJ2 } \\
\hline $\mathrm{A} 1$ & $0-10$ & 7.5YR $3 / 2$ & $\mathrm{mfc}, \mathrm{gr}$ & mf, mpl, Ipj & $\mathrm{cl}, \mathrm{pn}$ & 647 & 287 & 67 & FA \\
\hline$A B$ & $10-22$ & $7.5 Y R 3 / 3$ & fc, $p q / g d, b s a / g r$ & $\mathrm{f}, \mathrm{pl}, \mathrm{lpj}$ & $\mathrm{cl}, \mathrm{pn}$ & 557 & 380 & 64 & FA \\
\hline $\mathrm{BA}$ & $22-32$ & 7.5YR 3/4 & fc, pq/med, bsa/gr & $f,|l p l| l p j$, & gl, pn & 535 & 338 & 127 & FA \\
\hline B1 & $32-52$ & $5 Y R 4 / 4$ & fc, pq/med, bsa/gr & $\mathrm{f}, \mathrm{pl}, \mathrm{pj}$ & $\mathrm{gl}, \mathrm{pn}$ & 524 & 335 & 141 & $\mathrm{~F}$ \\
\hline B2 & $52-64$ & 5YR $4 / 6$ & $\mathrm{fc}, \mathrm{pq} / \mathrm{gd}, \mathrm{bsa} / \mathrm{gr}$ & $\mathrm{f}, \mathrm{Ipl}, \mathrm{pj}$ & gl, pn & 501 & 289 & 211 & $\mathrm{~F}$ \\
\hline B3 & $64-100$ & $7.5 Y R$ 4/6 & mod, pq/gd, bsa/gr & fm, Ipl, Ipj & $\mathrm{gl}, \mathrm{pn}$ & 505 & 272 & 223 & FAA \\
\hline
\end{tabular}

O quartzo corresponde a $74 \%$, caulinita a $17 \%$, illita a 1,2\%, hematita + goethita, anatásio e albita mostram concentrações inferiores a $1 \%$ (Tabela 3).

Os perfis de solos adjacentes 1 e 2 são constituídos também por quartzo, caulinita, goethita, hematita, anatásio e illita. No entanto, illita foi reconhecida somente nas lâminas orientadas. O horizonte subsuperficial também mostra os picos mais desenvolvidos de caulinita (Figura 3 e 4). Os dados semiquantitativos revelam valores altos de quartzo e caulinita nos horizontes A e B, respectivamente. O quartzo apresenta 73\%, caulinita 19\%, hematita + goethita e illita em torno de 1,7\% enquanto que o anatásio apresenta concentração média menor que 1\% (Tabela 3).

\section{Elementos maiores, menores e traços Solo com TPA}

Os solos são compostos principalmente por $\mathrm{SiO}_{2}(820-878$ $\left.\mathrm{g} \mathrm{kg}^{-1}\right), \mathrm{Al}_{2} \mathrm{O}_{3}\left(42-119 \mathrm{~g} \mathrm{~kg}^{-1}\right), \mathrm{Fe}_{2} \mathrm{O}_{3}\left(4,2-12 \mathrm{~g} \mathrm{~kg}^{-1}\right), \mathrm{TiO}_{2}$ (5,5-8,8 $\left.\mathrm{g} \mathrm{kg}^{-1}\right), \mathrm{CaO}\left(0,7-5,1 \mathrm{~g} \mathrm{~kg}^{-1}\right)$ e $\mathrm{K}_{2} \mathrm{O}\left(1,3-1,8 \mathrm{~g} \mathrm{~kg}^{-1}\right)$. Além disso, $\mathrm{MgO}\left(0,5-0,8 \mathrm{~g} \mathrm{~kg}^{-1}\right), \mathrm{Na}_{2} \mathrm{O}\left(0,2-0,9 \mathrm{~g} \mathrm{~kg}^{-1}\right), \mathrm{P}_{2} \mathrm{O}_{5}$ $\left(0,2-0,6 \mathrm{~g} \mathrm{~kg}^{-1}\right)$ e $\mathrm{MnO}\left(0,1 \mathrm{~g} \mathrm{~kg}^{-1}\right)$ ocorrem em concentraçóes 
mais baixas (teores totais). O C orgânico apresenta teores de 72 $\mathrm{g} \mathrm{kg}^{-1}$ no horizonte superficial, e uma diminuição para $69 \mathrm{~g} \mathrm{~kg}^{-1}$ e $11 \mathrm{~g} \mathrm{~kg}^{-1}$ no horizonte subsuperficial. Os elementos traços (teores traço) apresentam três perfis de concentração distintos: $\mathrm{Cu}, \mathrm{Ba}, \mathrm{Sr}$ e $\mathrm{Zn}$ aumentam do horizonte subsuperficial para o superficial, V, Ni, Cr e Zr diminuem do subsuperficial para o superficial e $\mathrm{Be}, \mathrm{Sc}, \mathrm{Y}$, Co e $\mathrm{Pb}$ são relativamente similares ao longo do perfil de solo (Tabela 4).

As concentraçóes de $\mathrm{SiO}_{2}$ e $\mathrm{Al}_{2} \mathrm{O}_{3}$ diminuem do horizonte $\mathrm{B}$ até o horizonte $\mathrm{A}$ e são inversamente proporcionais ao $\mathrm{C}$ orgânico (Figura 5a), reflexo de uma influência relativamente menor de argilominerais (caulinita) desestabilizados pelo conteúdo elevado de matéria orgânica no horizonte superficial (e.g. Costa e Kern 1999). Em geral, as concentraçôes de $\mathrm{SiO}_{2}$ e $\mathrm{Al}_{2} \mathrm{O}_{3}$ são inversamente proporcionais, uma vez que é produto do antagonismo entre quartzo e argilominerais. Os picos menos desenvolvidos da caulinita no horizonte A e o coeficiente de correlação entre $\mathrm{SiO}_{2}$ e $\mathrm{Al}_{2} \mathrm{O}_{3}(0,59)$ e $\mathrm{Al}_{2} \mathrm{O}_{3}$ e $\mathrm{CO}(-0,81)$ sustentam estas interpretaçóes. As concentraçóes de $\mathrm{Al}_{2} \mathrm{O}_{3}$ e o coeficiente entre $\mathrm{Al}_{2} \mathrm{O}_{3}$ e $\mathrm{K}_{2} \mathrm{O}$ $(0,65)$ podem indicar uma contribuiçáo da presença de illita que se distingue dos outros minerais de argila do grupo da mica pela concentração mais elevada em potássio.

As concentraçóes de $\mathrm{TiO}_{2}$ e $\mathrm{Fe}_{2} \mathrm{O}_{3}$ diminuem do horizonte $\mathrm{B}$ para o horizonte A (Figura 5a) e podem estar relacionadas com anatásio e hematita/goethita, respectivamente. Além disso, correlaçóes são esperadas entre os metais de transição como $\mathrm{Fe}_{2} \mathrm{O}_{3}$ e Ni $(0,95), \mathrm{Fe}_{2} \mathrm{O}_{3}$ e V $(0,95), \mathrm{Fe}_{2} \mathrm{O}_{3}$ e $\mathrm{Cr}(0,82)$ e $\mathrm{Fe}_{2} \mathrm{O}_{3}$ e $\mathrm{Zr}(0,62)$, que devem ocorrer associados aos oxihidróxidos de ferro. $\mathrm{O}$ coeficiente de correlação entre $\mathrm{Al}_{2} \mathrm{O}_{3}$ e $\mathrm{Na}_{2} \mathrm{O}(0,92)$ sugere uma contribuiçáo parcial da albita, uma vez que concentraçóes de $\mathrm{Na}_{2} \mathrm{O}$ também são menores no horizonte A (Figura 5b). As concentraçôes altas de $\mathrm{P}_{2} \mathrm{O}_{5}$ e a correlação negativa entre $\mathrm{Al}_{2} \mathrm{O}_{3}$ e $\mathrm{P}_{2} \mathrm{O}_{5}(-0,37)$ podem indicar uma correspondência forte com resíduos orgânicos. Adicionalmente, as concentraçóes altas de $\mathrm{CaO}$ no horizonte A (Figura 5b) e os coeficientes entre $\mathrm{CaO}$ e $\mathrm{Sr}(0,84)$ e $\mathrm{CaO}$ e $\mathrm{Ba}(0,80)$ podem também estar relacionados aos artefatos cerâmicos, resíduos vegetais e animais (Costa et al. 2004a e b).

$\mathrm{O}$ empobrecimento de $\mathrm{K}_{2} \mathrm{O}, \mathrm{Na}_{2} \mathrm{O}, \mathrm{TiO}_{2}, \mathrm{Fe}_{2} \mathrm{O}_{3}, \mathrm{Ni}, \mathrm{V}$, $\mathrm{Cr}$ e $\mathrm{Zr}$ no horizonte A é típico de perfis de solos Amazônicos (Lima 2001). Entretanto, as concentraçôes relativamente altas de $\mathrm{CaO}, \mathrm{MgO}, \mathrm{MnO}, \mathrm{P}_{2} \mathrm{O}_{5}, \mathrm{Zn}, \mathrm{Cu}, \mathrm{Ba}$ e Sr sugerem modificação do horizonte $\mathrm{A}$ através da formação da TPA.

\section{Solos adjacentes}

As amostras de solo apresentam principalmente $\mathrm{SiO}_{2}$ (796-866 g kg $\left.{ }^{-1}\right), \mathrm{Al}_{2} \mathrm{O}_{3}\left(62-96 \mathrm{~g} \mathrm{~kg}^{-1}\right), \mathrm{Fe}_{2} \mathrm{O}_{3}\left(11-29 \mathrm{~g} \mathrm{~kg}^{-1}\right)$, $\mathrm{TiO}_{2}\left(3,6-5,1 \mathrm{~g} \mathrm{~kg}^{-1}\right)$ e $\mathrm{K}_{2} \mathrm{O}\left(1,7-2,5 \mathrm{~g} \mathrm{~kg}^{-1}\right)$ e $\mathrm{MnO}(1,1-2,9$
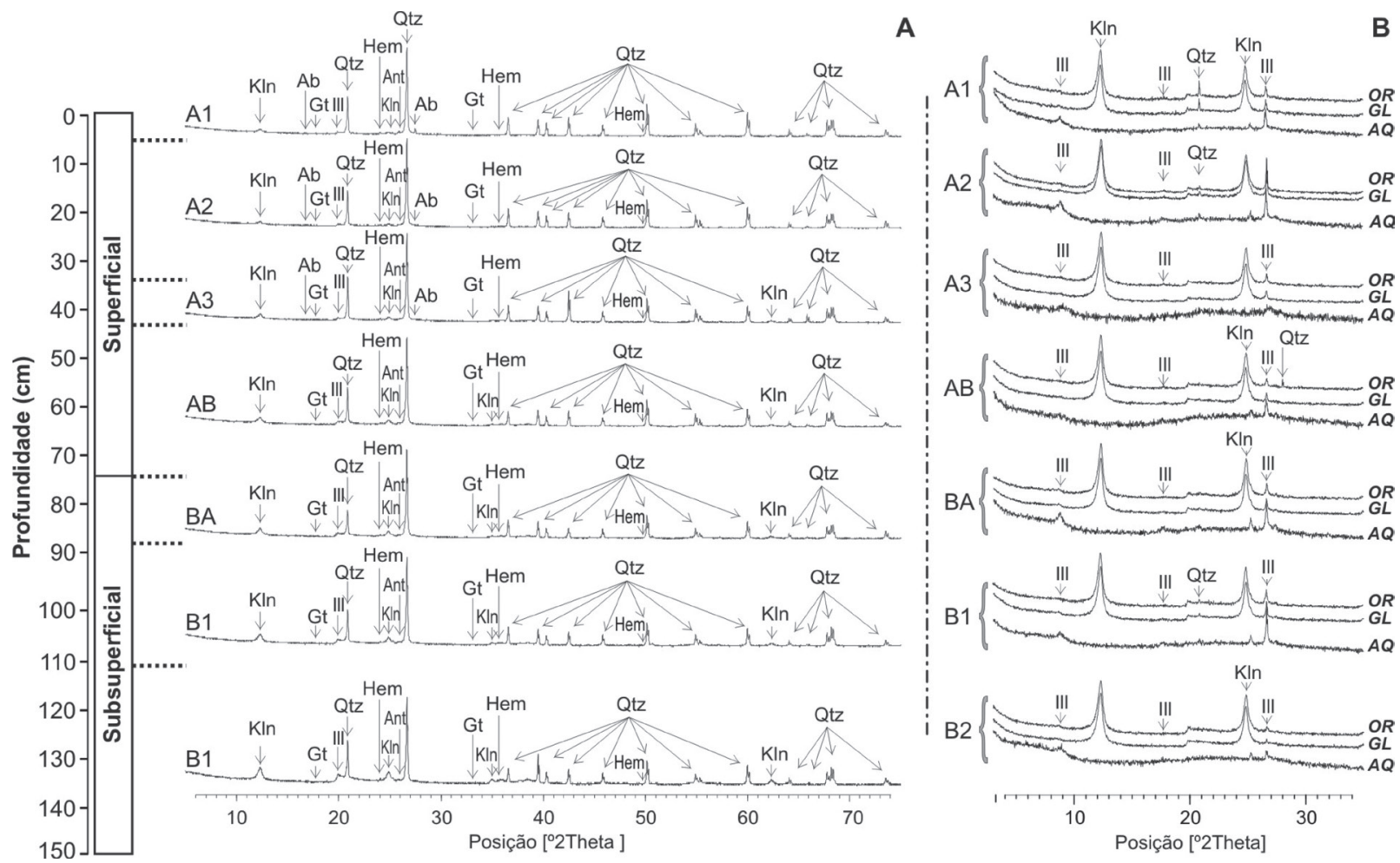

Figura 2- Padrões de DRX com os principais minerais identificados através do (A) método do pó e (B) pipette-on-glass do solo com Terra Preta Arqueológica (TPA). KIn: caulinita; Ab: albita; Gt: Goethita; Ill: illita; Qtz: quartzo; Hem: hematita; Ant: anatásio; OR: orientada; GL: glicolada; AQ: aquecida. 


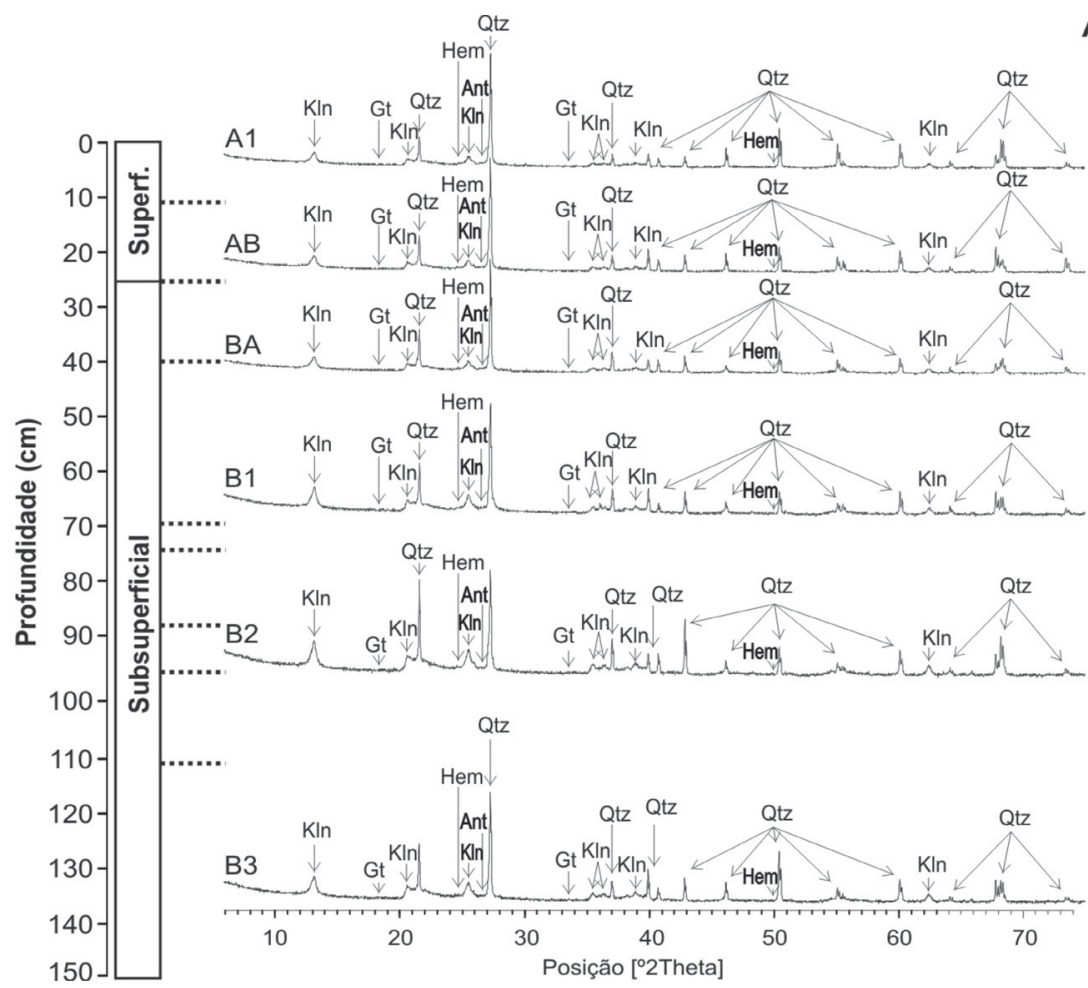

A

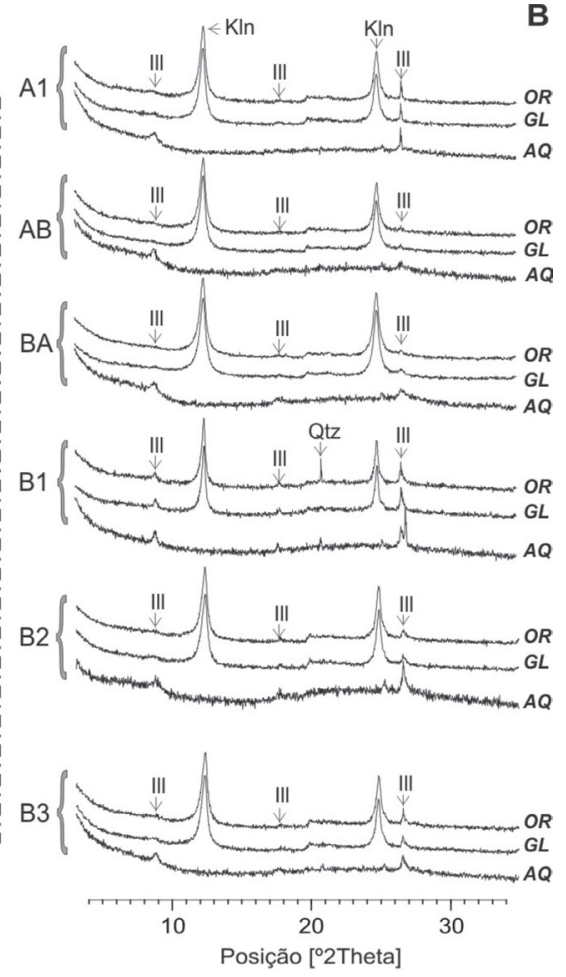

Figura 3- Padrões de DRX com os principais minerais identificados através do (A) método do pó e (B) pipette-on-glass do solo adjacente 1. Kln: caulinita; Gt: Goethita; III: illita; Qtz: quartzo; Hem: hematita; Ant: anatásio; OR: orientada; GL: glicolada; AQ: aquecida.
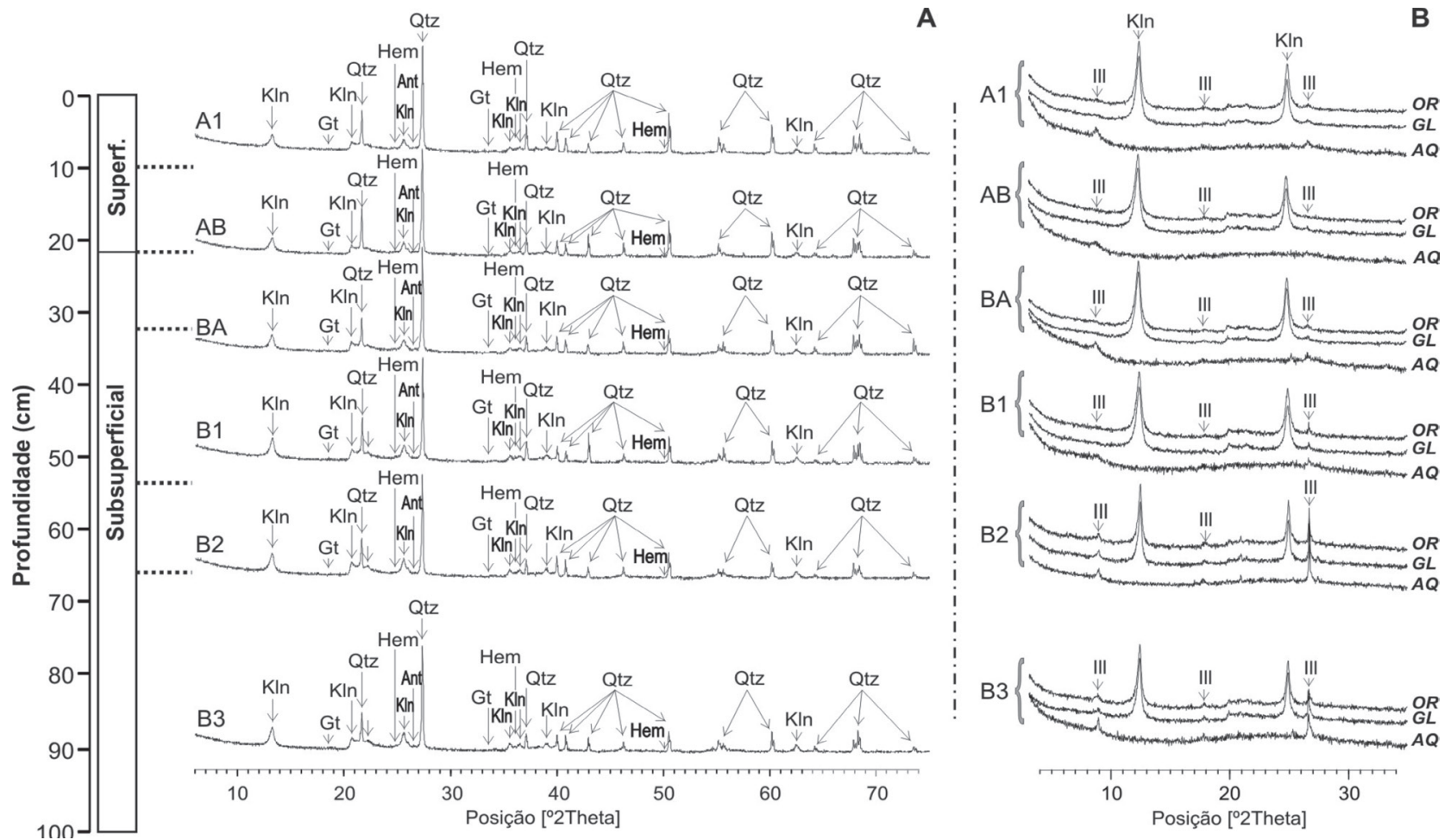

Figura 4- Padrões de DRX com os principais minerais identificados através do (A) método do pó e (B) pipette-on-glass do solo adjacente 2.KIn: caulinita; Gt: Goethita; III: illita; Qtz: quartzo; Hem: hematita; Ant: anatásio; OR: orientada; GL: glicolada; AQ: aquecida. 
Tabela 3- Composição mineralógica dos perfis de solo do sítio BJ8.

\begin{tabular}{|c|c|c|c|c|c|c|}
\hline Horizonte & Quartzo & Caulinita & $\begin{array}{l}\text { Hematita } \\
\text { + Goethita }\end{array}$ & Illita & Anatásio & Albita \\
\hline \multicolumn{7}{|c|}{ Solo com Terra Preta Arqueológica (TPA) } \\
\hline A1 & 80,58 & 9,67 & 0,53 & 1,27 & 0,55 & 0,17 \\
\hline A2 & 83,49 & 7,44 & 0,42 & 1,10 & 0,57 & 0,17 \\
\hline A3 & 76,59 & 13,92 & 0,58 & 1,10 & 0,71 & 0,17 \\
\hline$A B$ & 69,63 & 21,36 & 0,84 & 1,10 & 0,70 & 0 \\
\hline BA & 72,16 & 18,43 & 0,75 & 1,10 & 0,69 & 0 \\
\hline B1 & 71,95 & 22,96 & 1,01 & 1,35 & 0,84 & 0 \\
\hline B2 & 66,13 & 29,19 & 1,22 & 1,52 & 0,88 & 0 \\
\hline \multicolumn{7}{|c|}{ Solos adjacentes } \\
\hline A1 & 77,08 & 14,88 & 1,40 & 1,52 & 0,47 & \\
\hline$A B$ & 74,90 & 16,88 & 1,71 & 1,52 & 0,43 & \\
\hline BA & 72,55 & 19,06 & 1,83 & 1,69 & 0,47 & \\
\hline B1 & 70,60 & 20,15 & 1,84 & 1,78 & 0,44 & \\
\hline B2 & 70,99 & 20,96 & 2,01 & 1,86 & 0,42 & \\
\hline B3 & 71,91 & 22,35 & 2,24 & 2,03 & 0,44 & \\
\hline
\end{tabular}

Tabela 4-Concentração dos elementos maiores, menores e traços ao longo dos horizontes do solo com Terra Preta Arqueológica (TPA).

\begin{tabular}{|c|c|c|c|c|c|c|c|}
\hline Elementos & $\mathrm{A} 1$ & $\mathrm{~A} 2$ & A3 & $A B$ & BA & B1 & B2 \\
\hline \multicolumn{8}{|c|}{$\mathrm{g} \mathrm{kg}^{-1}$} \\
\hline $\mathrm{SiO}_{2}$ & 820,0 & 833,6 & 824,5 & 804,9 & 830,4 & 877,9 & 875,2 \\
\hline $\mathrm{Al}_{2} \mathrm{O}_{3}$ & 41,8 & 32,5 & 58,1 & 87,2 & 75,6 & 94,2 & 119,2 \\
\hline $\mathrm{Fe}_{2} \mathrm{O}_{3}$ & 5,3 & 4,2 & 5,8 & 8,4 & 7,5 & 10,1 & 12,2 \\
\hline $\mathrm{TiO}_{2}$ & 5,50 & 5,70 & 7,10 & 6,95 & 6,90 & 8,35 & 8,75 \\
\hline $\mathrm{CaO}$ & 5,10 & 3,00 & 1,50 & 1,20 & 0,60 & 0,80 & 0,70 \\
\hline $\mathrm{K}_{2} \mathrm{O}$ & 1,45 & 1,30 & 1,30 & 1,30 & 1,25 & 1,60 & 1,75 \\
\hline $\mathrm{MgO}$ & 0,81 & 0,47 & 0,50 & 0,60 & 0,55 & 0,64 & 0,68 \\
\hline $\mathrm{Na}_{2} \mathrm{O}$ & 0,20 & 0,20 & 0,20 & 0,40 & 0,40 & 0,50 & 0,90 \\
\hline $\mathrm{P}_{2} \mathrm{O}_{5}$ & 0,56 & 0,23 & 0,20 & 0,19 & 0,15 & 0,22 & 0,26 \\
\hline $\mathrm{MnO}$ & 1,11 & 0,94 & 0,70 & 0,43 & 0,23 & 0,23 & 0,15 \\
\hline $\mathrm{CO}$ & 72,30 & 68,10 & 69,30 & 63,70 & 68,70 & 18,90 & 10,60 \\
\hline \multicolumn{8}{|c|}{$\mathrm{mg} \mathrm{kg}-1$} \\
\hline $\mathrm{Zr}$ & 111 & 172 & 171 & 212 & 114 & 203 & 218 \\
\hline $\mathrm{Zn}$ & 107 & 84 & 79 & 80 & 68 & 87 & 80 \\
\hline $\mathrm{Ba}$ & 90 & 87 & 70 & 72 & 39 & 65 & 65 \\
\hline V & 20 & 21 & 25 & 36 & 23 & 39 & 48 \\
\hline $\mathrm{Sr}$ & 33 & 24 & 18 & 21 & 12 & 20 & 23 \\
\hline $\mathrm{Cu}$ & 28 & 29 & 22 & 20 & 19 & 19 & 19 \\
\hline $\mathrm{Cr}$ & 14 & 12 & 16 & 23 & 11 & 21 & 25 \\
\hline $\mathrm{Ni}$ & 12 & 11 & 13 & 21 & 13 & 23 & 30 \\
\hline $\mathrm{Pb}$ & 11 & 9 & 10 & 11 & 8 & 12 & 10 \\
\hline Y & 7 & 8 & 8 & 9 & 5 & 9 & 7 \\
\hline Sc & 5 & 5 & 6 & 8 & 5 & 8 & 9 \\
\hline Co & 8 & 8 & 8 & 8 & 8 & 8 & 8 \\
\hline $\mathrm{Be}$ & 3 & 3 & 3 & 3 & 3 & 3 & 3 \\
\hline
\end{tabular}
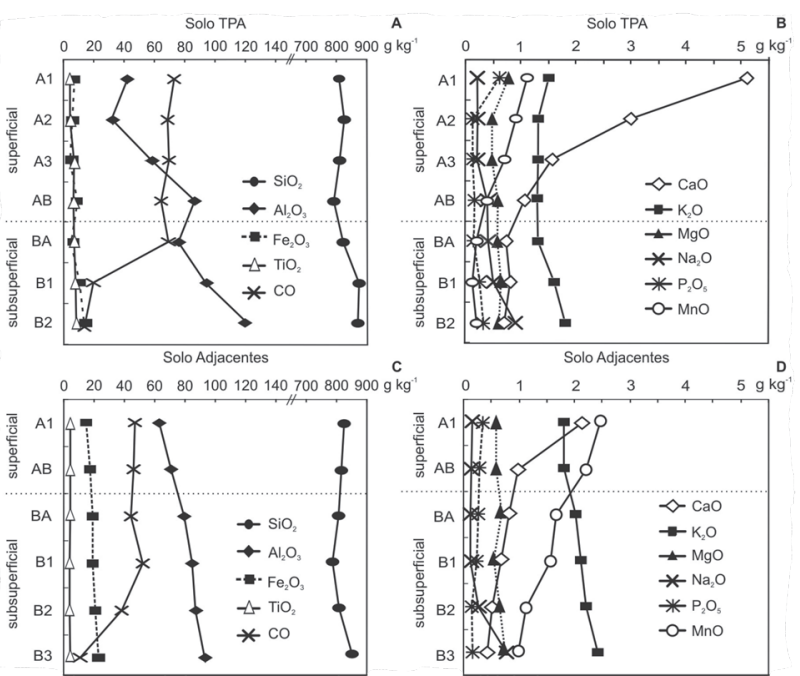

Figura 5- A) Concentrações dos elementos maiores (teores totais) no solo com TPA; B) Concentrações dos elementos menores (teores menores) no solo com TPA; C) Concentrações médias dos elementos maiores (teores totais) nos solos adjacentes; D) Concentrações médias dos elementos menores (teores menores) nos solos adjacentes.

$\left.\mathrm{g} \mathrm{kg}^{-1}\right) \cdot \mathrm{CaO}\left(0,3-2,3 \mathrm{~g} \mathrm{~kg}^{-1}\right), \mathrm{Na}_{2} \mathrm{O}\left(0,2-1,2 \mathrm{~g} \mathrm{~kg}^{-1}\right), \mathrm{MgO}$ $\left(\sim 0,6 \mathrm{~g} \mathrm{~kg}^{-1}\right)$ e $\mathrm{P}_{2} \mathrm{O}_{5}\left(0,1-0,3 \mathrm{~g} \mathrm{~kg}^{-1}\right)$ possuem concentraçōes menores (teores totais). $\mathrm{O} C$ orgânico varia entre de $7,4 \mathrm{~g} \mathrm{~kg}^{-1}$ a $69 \mathrm{~g} \mathrm{~kg}^{-1}$ no horizonte $\mathrm{B}$, seguido de teores em torno de 30 $\mathrm{g} \mathrm{kg}^{-1}$ e $70 \mathrm{~g} \mathrm{~kg}^{-1}$ no horizonte A. Os elementos traços (teores traços) revelam concentraçôes homogêneas em todo o perfil de solo, com diferenças pequenas de $\mathrm{Zr}, \mathrm{Cu}, \mathrm{Cr}, \mathrm{Ni}, \mathrm{V}$, Ba e Zn do horizonte B para o A (Tabela 5).

$\mathrm{SiO}_{2}$ e $\mathrm{Al}_{2} \mathrm{O}_{3}$ são os mais abundantes (Figura 5c), e constituem o quartzo e argilominerais como a caulinita e illita. Os maiores teores da fração fina e o coeficiente de correlação entre $\mathrm{SiO}_{2}$ e $\mathrm{Al}_{2} \mathrm{O}_{3}(-0,01)$ e $\mathrm{SiO}_{2}$ e $\mathrm{Zr}(0,05)$ correspondem a menor contribuiçáo da fraçáo areia que o solo com TPA. As concentraçôes de $\mathrm{SiO}_{2}$ e carbono orgânico, e o coeficiente entre $\mathrm{SiO}_{2}$ e $\mathrm{CO}(-0,82)$ evidenciam a sinergia entre a matéria orgânica e argila. As concentraçóes de $\mathrm{Al}_{2} \mathrm{O}_{3}$ diminuem suavemente do horizonte $\mathrm{B}$ para o horizonte $\mathrm{A}$ (Figura $5 \mathrm{c}$ ), mas os coeficientes entre $\mathrm{Al}_{2} \mathrm{O}_{3}$ e $\mathrm{K}_{2} \mathrm{O}(0,96)$ e $\mathrm{Al}_{2} \mathrm{O}_{3}$ e $\mathrm{MgO}(0,85)$ ainda comprovam a presença de illita. As concentraçóes de $\mathrm{Fe}_{2} \mathrm{O}_{3}$, os coeficientes entre $\mathrm{Fe}_{2} \mathrm{O}_{3}$ e $\mathrm{Ni}(0,94), \mathrm{Fe}_{2} \mathrm{O}_{3}$ eV $(0,64)$ e $\mathrm{Fe}_{2} \mathrm{O}_{3}$ e $\mathrm{Cr}(0,34)$ podem ser correlacionados com hematita e goethita. $\mathrm{TiO}_{2}$ não demonstrou oscilaçôes significativas e provavelmente corresponde ao anatásio. As concentraçóes de $\mathrm{P}_{2} \mathrm{O}_{5}$ são menores que o solo com TPA (Figura $5 \mathrm{~d}$ ). Além disso, o coeficiente entre $\mathrm{P}_{2} \mathrm{O}_{5}$ e $\mathrm{Al}_{2} \mathrm{O}_{3}(-0,91)$, o aumento de $\mathrm{CaO}, \mathrm{P}_{2} \mathrm{O}_{5}$ e $\mathrm{MnO}$ do horizonte $\mathrm{B}$ para o horizonte $\mathrm{A}$ e correlaçáo positiva destes elementos com carbono orgânico $(\sim 0,40)$ revelam correspondência maior com a fração orgânica do solo, enquanto que $\mathrm{Al}_{2} \mathrm{O}_{3}, \mathrm{~K} 2 \mathrm{O}, \mathrm{Ni}, \mathrm{MgO}, \mathrm{Fe}_{2} \mathrm{O}_{3}, \mathrm{Zn}$ e Cr mostram concentraçóes mais baixas no horizonte superficial. 
Tabela 5-Concentração média dos elementos maiores, menores e traços ao longo dos horizontes dos solos adjacentes.

\begin{tabular}{|c|c|c|c|c|c|c|}
\hline Elementos & $\mathrm{A} 1$ & $A B$ & $\mathrm{BA}$ & $\mathrm{B} 1$ & B2 & B3 \\
\hline \multicolumn{7}{|c|}{$\mathrm{g} \mathrm{kg}^{-1}$} \\
\hline $\mathrm{SiO}_{2}$ & 830,8 & 823,2 & 815,8 & 797,8 & 817,9 & 856,2 \\
\hline $\mathrm{Al}_{2} \mathrm{O}_{3}$ & 62,7 & 70,6 & 79,6 & 84,2 & 87,6 & 93,5 \\
\hline $\mathrm{Fe}_{2} \mathrm{O}_{3}$ & 14,0 & 17,1 & 18,3 & 18,4 & 20,1 & 22,4 \\
\hline $\mathrm{TiO}_{2}$ & 4,65 & 4,32 & 4,69 & 4,44 & 4,15 & 4,35 \\
\hline $\mathrm{CaO}$ & 2,10 & 1,02 & 0,80 & 0,61 & 0,49 & 0,44 \\
\hline $\mathrm{K}_{2} \mathrm{O}$ & 1,77 & 1,83 & 1,97 & 2,07 & 2,20 & 2,36 \\
\hline $\mathrm{MgO}$ & 0,60 & 0,59 & 0,65 & 0,64 & 0,65 & 0,70 \\
\hline $\mathrm{Na}_{2} \mathrm{O}$ & 0,18 & 0,17 & 0,18 & 0,17 & 0,21 & 0,67 \\
\hline $\mathrm{P}_{2} \mathrm{O}_{5}$ & 0,30 & 0,23 & 0,18 & 0,13 & 0,14 & 0,13 \\
\hline $\mathrm{MnO}$ & 2,39 & 2,05 & 1,72 & 1,57 & 1,23 & 1,01 \\
\hline $\mathrm{CO}$ & 46,50 & 45,55 & 43,95 & 51,90 & 37,60 & 10,30 \\
\hline \multicolumn{7}{|c|}{$\mathrm{mg} \mathrm{kg}^{-1}$} \\
\hline $\mathrm{Zr}$ & 171 & 165 & 167 & 159 & 148 & 175 \\
\hline $\mathrm{Ba}$ & 96 & 89 & 87 & 86 & 87 & 95 \\
\hline $\mathrm{Zn}$ & 56 & 61 & 62 & 66 & 68 & 71 \\
\hline $\mathrm{Cu}$ & 56 & 47 & 31 & 29 & 28 & 30 \\
\hline V & 37 & 42 & 45 & 46 & 48 & 57 \\
\hline $\mathrm{Ni}$ & 30 & 34 & 35 & 36 & 41 & 44 \\
\hline $\mathrm{Sr}$ & 32 & 27 & 26 & 27 & 28 & 30 \\
\hline $\mathrm{Cr}$ & 16 & 18 & 17 & 17 & 19 & 18 \\
\hline Co & 13 & 14 & 14 & 15 & 14 & 13 \\
\hline Y & 11 & 12 & 12 & 12 & 12 & 13 \\
\hline $\mathrm{Pb}$ & 11 & 13 & 11 & 12 & 9 & 10 \\
\hline Sc & 8 & 9 & 10 & 11 & 11 & 13 \\
\hline $\mathrm{Be}$ & 3 & 3 & 3 & 3 & 3 & 3 \\
\hline
\end{tabular}

Os elementos $\mathrm{Ba}, \mathrm{Sr}, \mathrm{Zn}$ e $\mathrm{MgO}$ foram relacionados a resíduos vegetais e animais no solo TPA, contudo o coeficiente negativo entre estes elementos e o $\mathrm{C}$ orgânico podem indicar uma associação maior com argilominerais e oxi-hidróxidos de ferro.

\section{Associações químicas}

A análise estatística do grau de similaridade dos dados identificou três principais associaçôes no solo com TPA (Figura 6a): associação $1\left(\mathrm{Al}_{2} \mathrm{O}_{3}-\mathrm{Fe}_{2} \mathrm{O}_{3}-\mathrm{V}-\mathrm{Ni}_{-} \mathrm{Na}_{2} \mathrm{O}-\mathrm{Cr}-\mathrm{TiO}_{2}\right.$ $\left.\mathrm{Zr}-\mathrm{K}_{2} \mathrm{O}\right)$ com elementos que estáo bem correlacionados com argilominerais e oxi-hidróxidos de ferro; associação 2 (MgO$\mathrm{CaO}-\mathrm{MnO}-\mathrm{Cu}-\mathrm{P}_{2} \mathrm{O}_{5}-\mathrm{Ba}-\mathrm{Sr}-\mathrm{Zn}-\mathrm{CO}$ ) com as concentraçôes mais altas no horizonte $\mathrm{A}$ e indica os materiais que podem ter sido introduzidos pela população pré-histórica (utensílios de cozinha, alimentos e outros materiais de origem vegetal e animal) com alteração parcial após o descarte, além dos processos pedogenéticos subseqüentes relacionados com os teores altos de carbono orgânico; e a associação 3 (Be-Sc$\mathrm{Y}-\mathrm{Co}-\mathrm{Pb}$ ) mostra concentração e padrão de distribuição similar ao longo do perfil de solo, e náo foi influenciada pela formação da TPA.
Nos solos adjacentes (Figura 6b) as três principais associaçôes identificadas foram: associação $1\left(\mathrm{Al}_{2} \mathrm{O}_{3}-\mathrm{K}_{2} \mathrm{O}\right.$ $\mathrm{Ni}-\mathrm{MgO}-\mathrm{Fe}_{2} \mathrm{O}_{3}-\mathrm{Zn}-\mathrm{Na}_{2} \mathrm{O}-\mathrm{V}-\mathrm{TiO}_{2}-\mathrm{Zr}-\mathrm{Cr}-\mathrm{Ba}$ ) correlacionada com caulinita, illita e hematita/goethita; associaçâo $2(\mathrm{CaO}-$ $\left.\mathrm{P}_{2} \mathrm{O}_{5}-\mathrm{MnO}-\mathrm{Cu}-\mathrm{CO}\right)$ possui relação maior com material orgânico do solo; associaçáo 3 (Be-Sc-Y-Co-Pb-Sr) não demonstrou variaçóes significativas entre os horizontes do solo, características estas que são semelhantes aos solos amazônicos com cobertura vegetal (Lima 2001).

\section{Parâmetros de fertilidade}

$\mathrm{O}$ pH do solo com TPA em $\mathrm{KCl}(\bar{x}=5,3)$ e $\mathrm{H}_{2} \mathrm{O}$ $(\bar{x}=6,3)$ resultou em $\Delta \mathrm{pH}$ negativo. Contudo, valores de $\mathrm{pH}$ ligeiramente maiores que a média e $\Delta \mathrm{pH}$ foram encontrados no horizonte superficial. Os elementos disponíveis (teores disponíveis) $\mathrm{Mn}$ e $\mathrm{Zn}$ possuem concentraçôes maiores no horizonte superficial, mas o P disponível revela comportamento relativamente inverso e influência nos horizontes subsuperficiais do solo. $\mathrm{Fe}, \mathrm{Cu}$ disponível não mostram variações significativas. Com relação à concentração dos elementos trocáveis (teores trocáveis), $\mathrm{Ca}, \mathrm{Mg}, \mathrm{K}$ e Na aumentam levemente em direção ao horizonte superficial, enquanto $\mathrm{Al}$ não foi detectado. Assim, a acidez potencial (0,6-1,9 $\left.\mathrm{cmol} \mathrm{kg}^{-1}\right), \mathrm{Ca}^{2+}+\mathrm{Mg}^{2+}\left(2,3-9,6 \mathrm{cmol} \mathrm{kg}{ }^{-1}\right), \mathrm{SB}$ $\left(2,1-9,9 \mathrm{cmol} \mathrm{kg}^{-1}\right)$, CTC $\left(2,7-11,7 \mathrm{cmol} \mathrm{kg}^{-1}\right)$ apresentam padráo similar aos elementos trocáveis que resultou em $\mathrm{V} \geq 75 \%$ (Tabela 6). A presença de argilominerais, os teores de $\mathrm{C}$ orgânico e $\Delta \mathrm{pH}$ negativo indicam capacidade elevada de adsorção de cátions no solo. Os argilominerais caulinita 1:1 e ilita 2:1 identificados no solo com TPA possuem CTC baixa e moderada, respectivamente. Além disso, $\mathrm{Mn}, \mathrm{Zn}$ e $\mathrm{Cu}$ disponível apresentam coeficiente de correlaçẫo positiva com o C orgânico $(-0,50)$, assim como Ca, $\mathrm{Mg}$ e K trocável $(-0,40)$, mas $\mathrm{Fe}$ demonstra correlação positiva com $\mathrm{Fe}_{2} \mathrm{O}_{3}(0,76)$ e o $\mathrm{P}$ disponível com $\mathrm{P}_{2} \mathrm{O}_{5}(0,30)$. Ca e $\mathrm{Mg}$ trocáveis também apresentam coeficiente alto com $\mathrm{CaO}(0,99)$ e $\mathrm{MgO}(0,69)$, respectivamente. Desta forma, a distribuiçấo desses elementos pode estar relacionada com carbono orgânico, $\mathrm{Fe}_{2} \mathrm{O}_{3}, \mathrm{P}_{2} \mathrm{O}_{5}$, $\mathrm{CaO}, \mathrm{MgO}$ e argilominerais, principalmente ilita.

Com relaçáo aos solos adjacentes, o $\mathrm{pH}$ em $\mathrm{KCl}(\overline{\mathrm{x}}=6,2)$ e $\mathrm{H}_{2} \mathrm{O}(\overline{\mathrm{x}}=5,1)$ é menor que o solo com TPA e também resultou em $\Delta \mathrm{pH}$ negativo. Os elementos disponíveis $\mathrm{Mn}$, $\mathrm{Fe}, \mathrm{Zn}, \mathrm{P}$ e $\mathrm{Cu}$ apresentam concentraçôes relativamente maiores no horizonte superficial. Os elementos trocáveis possuem concentraçôes semelhantes ao solo com TPA, exceto $\mathrm{Ca}$ e $\mathrm{Mg}$ trocável. Al trocável também não foi detectado. Acidez potencial $\left(1-3,4 \mathrm{cmol} \mathrm{kg}^{-1}\right)$ e CTC $(2,9-11 \mathrm{cmol}$ $\left.\mathrm{kg}^{-1}\right)$ são levemente maiores, enquanto $\mathrm{Ca}^{2+}+\mathrm{Mg}^{2+}(1,5-7,4$ cmol kg-1), SB (1,7-7,7 $\left.\mathrm{cmol} \mathrm{kg}^{-1}\right)$ e V (60-69\%) apresentam concentraçóes menores que o solo com TPA (Tabela 7). P, Mn e Cu disponível, Ca e Mg trocável podem ser correlacionados 

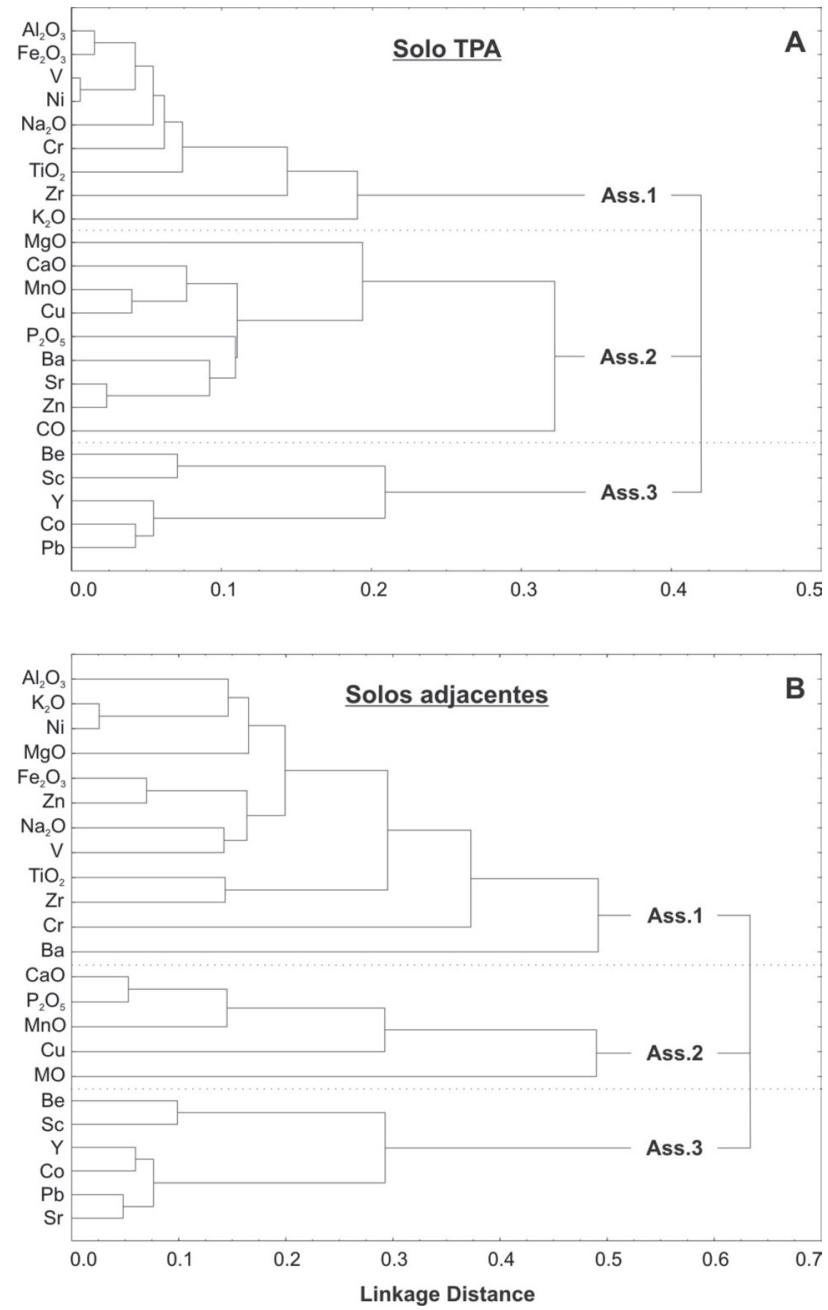

Figura 6- Análises de agrupamento para os elementos maiores, menores e traços no solo com Terra Preta Arqueológica (TPA) (A) e solos adjacentes (B).

com o C orgânico $(-0,35)$. Além disso, $\mathrm{Mn}, \mathrm{Cu}, \mathrm{P}$ disponível e Ca trocável também mostraram coeficiente relativamente alto com $\mathrm{MnO}(0,95), \mathrm{Cu}$ total $(0,46), \mathrm{P}_{2} \mathrm{O}_{5}(0,82)$ e $\mathrm{CaO}$ $(0,99)$, respectivamente.

A concentração de $\mathrm{P}$ disponível, assim como a concentração total nos solos com TPA e adjacentes são inferiores aos obtidos em outros sítios com TPA, tais como sítio Manduquinha (Kern 1996) e Ilha de Terra (Meireles 2004) na região de Caxiuanã. As maiores concentraçôes de P disponível foram obtidas nos horizontes superficiais dos perfis, especialmente no perfil TPA. Este tipo de distribuiçáo indica que a maior parte do P disponível provém da matéria orgânica, que é constituída principalmente por carbono, hidrogênio, oxigênio, enxofre e fósforo. A concentração de fósforo de origem inorgânica deve ser negligenciável, uma vez que as rochas que deram origem aos solos da região de Bom Jesus do Tocantins devem ser pobres em fósforo.

\section{Sistemas de classificação de solos e taxonomia da tpa e solos adjacentes}

Com base na presença do horizonte $\mathrm{B}$ textural abaixo do horizonte $\mathrm{A}$, argila de atividade baixa $\left(\overline{\mathrm{x}}=23,6 \mathrm{cmol} \mathrm{kg}^{-1}\right)$, matiz 7.5YR, V ( $\bar{x}=70 \%)$ no horizonte subsuperficial, e ausência de plintita, gleização, caráter plânico e sódico, os solos TPA e adjacentes podem ser classificados conforme o SiBCS até o subgrupo como ARGISSOLOS AMARELOS Eutróficos típicos. Além disso, a textura média, horizonte superficial com $25 \mathrm{~cm}$ de espessura e estrutura granular permitiram a definição de um horizonte A chernozêmico para os solos adjacentes. Textura arenosa/média, concentraçóes mais elevadas de $\mathrm{P}_{2} \mathrm{O}_{5}$ $\left(\overline{\mathrm{x}}=0,3 \mathrm{~g} \mathrm{~kg}^{-1}\right)$ e a presença de artefatos líticos e cerâmicos no horizonte superficial definem um horizonte A antrópico para o solo com TPA.

Segundo a correspondência aproximada com o Soil Taxonomy, os solos TPA e adjacentes podem ser considerados como Typic Kandiudox. No solo TPA, o horizonte diagnóstico superficial não pode ser descrito como antrópico, uma vez que os critérios para esta classificação requerem $1,5 \mathrm{~g} \mathrm{~kg}^{-1}$ ou mais de $\mathrm{P}_{2} \mathrm{O}_{5}$ e diminuição progressiva até uma profundidade de $125 \mathrm{~cm}$ (Soil Survey Staff 2010). Com relação à legenda FAO-WRB, os solos adjacentes são classificados como Haplic Lixisols. Requisitos desta legenda como Munsell value e chroma de 3 ou menos, $10 \mathrm{~g} \mathrm{~kg}^{-1}$ ou mais de C orgânico, $0,1 \mathrm{~g} \mathrm{~kg}^{-1}$ ou mais de $\mathrm{P}_{2} \mathrm{O}_{5}$ nos $25 \mathrm{~cm}$ superiores, $\mathrm{V} \geq 50 \%$ indicam a

Tabela 6-Concentração dos parâmetros de fertilidade ao longo dos horizontes do solo com Terra Preta Arqueológica (TPA).

\begin{tabular}{|c|c|c|c|c|c|c|c|}
\hline $\begin{array}{l}\text { Elementos/ } \\
\text { Horizontes }\end{array}$ & $\mathrm{A} 1$ & $\mathrm{~A} 2$ & A3 & $A B$ & $\mathrm{BA}$ & B1 & B2 \\
\hline $\mathrm{pH}-\mathrm{H}_{2} \mathrm{O}$ & 6,3 & 6,3 & 6,3 & 6,3 & 6,3 & 6,2 & 6,3 \\
\hline $\mathrm{pH}-\mathrm{KCl}$ & 5,6 & 5,4 & 5,3 & 5,1 & 5,1 & 5,1 & 5,2 \\
\hline$\Delta \mathrm{pH}$ & $-0,7$ & $-0,9$ & $-1,0$ & $-1,2$ & $-1,2$ & $-1,2$ & $-1,2$ \\
\hline $\mathrm{mg} \mathrm{kg}^{-1}$ & & & & & & & \\
\hline $\mathrm{Mn}_{\text {disponivel }}$ & 94 & 44 & 31 & 25 & 11 & 9 & 7 \\
\hline $\mathrm{P}_{\text {disponivel }}$ & 20 & 4 & 3 & 4 & 10 & 17 & 51 \\
\hline $\mathrm{Fe} e_{\text {disponivel }}^{\text {disponivel }}$ & 9 & 5 & 6 & 9 & 10 & 9 & 10 \\
\hline $\mathrm{Zn}$ disponivel & 8 & 3 & 2 & 1 & 0 & 0 & 0 \\
\hline $\mathrm{Cu}_{\text {disponivel }}$ & 0 & 2 & 2 & 2 & 2 & 1 & 1 \\
\hline \multicolumn{8}{|l|}{$\mathrm{cmol} \mathrm{kg}^{-1}$} \\
\hline $\mathrm{Ca}^{2+}$ & 8,3 & 5,3 & 3,4 & 2,6 & 2,2 & 2,0 & 2,2 \\
\hline $\mathrm{Mg}^{2+}$ & 1,3 & 0,3 & 0,1 & 0,1 & 0,1 & 0,1 & 0,1 \\
\hline $\mathrm{K}^{+}$ & 0,23 & 0,03 & 0,02 & 0,03 & 0,02 & 0,02 & 0,02 \\
\hline $\mathrm{Na}^{+}$ & 0,01 & 0,00 & 0,00 & 0,00 & 0,00 & 0,00 & 0,00 \\
\hline $\mathrm{Al}^{3+}$ & 0,0 & 0,0 & 0,0 & 0,0 & 0,0 & 0,0 & 0,0 \\
\hline $\mathrm{H}^{+}+\mathrm{Al}^{3+}$ & 1,9 & 1,8 & 0,8 & 0,8 & 0,8 & 0,6 & 0,6 \\
\hline SB & 9,9 & 5,6 & 3,5 & 2,8 & 2,4 & 2,1 & 2,3 \\
\hline $\mathrm{Ca}^{2+}+\mathrm{Mg}^{2+}$ & 9,6 & 5,6 & 3,5 & 2,8 & 2,3 & 2,1 & 2,3 \\
\hline CTC efetiva ( $\mathrm{t}$ ) & 9,86 & 5,59 & 3,51 & 2,78 & 2,35 & 2,11 & 2,32 \\
\hline $\begin{array}{l}\text { CTC potencial } \\
\text { (T) }\end{array}$ & 11,76 & 7,39 & 4,31 & 3,58 & 3,13 & 2,71 & 2,92 \\
\hline CTC (argila) & 639,13 & 293,25 & 86,20 & 36,91 & 29,81 & 21,85 & 17,49 \\
\hline \multicolumn{8}{|c|}{ 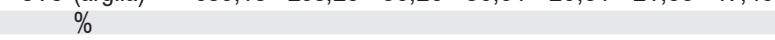 } \\
\hline V & 84 & 76 & 81 & 78 & 75 & 78 & 80 \\
\hline
\end{tabular}


presença de um horizonte hortic (FAO 2007). Desta forma, o solo com TPA pode ser classificado como Hortic Anthrosols.

Conforme a classificação da TPA através da legenda APC (Kämpf et al. 2003), o solo TPA corresponde aos requisitos do Culto-Hortic Archaeo-anthrosols, ebonic, sandy, mesotrophic, cumulic. Uma das problemáticas levantadas por estes autores para criação da legenda APC é a exclusão de diversos solos com TPA da classe Anthrosols pelo FAO-WRB (FAO 1998) devido à espessura $(\geq 50 \mathrm{~cm})$ requerida para o horizonte diagnóstico superficial. Entretanto, o critério diagnóstico proposto pela FAO-WRB (FAO 1998) envolve a identificação dos horizontes superficiais e subsuperficiais "antropedogênicos": terric, irragric, plaggic, hortic, anthraquic e hydragric, mas as espessuras limitantes são somente exigidas nos horizontes hortic e hydragric. O horizonte hortic deve apresentar $\mathrm{C}$ orgânico $(\geq 10$ $\left.\mathrm{g} \mathrm{kg}^{-1}\right)$ e $\mathrm{P}_{2} \mathrm{O}_{5}\left(>0,1 \mathrm{~g} \mathrm{~kg}^{-1}\right)$ nos $25 \mathrm{~cm}$ superiores (Gong et al. 1997) e o hydragric espessura $\geq 10 \mathrm{~cm}$. O hortic é um horizonte superficial modificado pelo homem através de um cultivo profundo, adubação intensiva e/ou introdução contínua de dejetos humanos e animais, e outros resíduos orgânicos e inorgânicos (e.g. utensílios cerâmicos de cozinha). O hydragric é um horizonte subsuperficial antrópico associado com cultivo úmido e apresenta geralmente feiçôes redoximórficas. $\mathrm{Na}$ atualização da FAO-WRB (FAO 2007) o horizonte Hortic

Tabela 7-Concentração média dos parâmetros de fertilidade ao longo dos horizontes dos solos adjacentes.

\begin{tabular}{|c|c|c|c|c|c|c|}
\hline $\begin{array}{l}\text { Elementos/ } \\
\text { Horizontes }\end{array}$ & $\mathrm{A} 1$ & $A B$ & $\mathrm{BA}$ & $\mathrm{B} 1$ & B2 & B3 \\
\hline $\mathrm{pH}-\mathrm{H}_{2} \mathrm{O}$ & 6,1 & 6,1 & 6,3 & 6,2 & 5,9 & 5,9 \\
\hline $\mathrm{pH}-\mathrm{KCl}$ & 5,2 & 5,1 & 5,1 & 5,1 & 4,9 & 5,0 \\
\hline$\Delta \mathrm{pH}$ & $-0,9$ & $-1,0$ & $-1,3$ & $-1,1$ & $-1,0$ & $-0,9$ \\
\hline \multicolumn{7}{|c|}{$\mathrm{mg} \mathrm{kg}^{-1}$} \\
\hline$M n_{\text {disponivel }}$ & 163 & 114 & 82 & 51 & 41 & 31 \\
\hline $\mathrm{Fe}_{\text {disponivel }}$ & 13 & 21 & 19 & 15 & 14 & 14 \\
\hline $\mathrm{P}_{\text {disponivel }}$ & 4 & 1 & 1 & 1 & 1 & 1 \\
\hline $\mathrm{Zn}$ disponivel & 4 & 1 & 1 & 0 & 0 & 0 \\
\hline $\mathrm{Cu}_{\text {disponivel }}$ & 2 & 2 & 2 & 2 & 1 & 1 \\
\hline \multicolumn{7}{|c|}{$\mathrm{cmol} \mathrm{kg}^{-1}$} \\
\hline $\mathrm{Ca}^{2+}$ & 6,5 & 3,1 & 1,9 & 1,5 & 1,1 & 1,0 \\
\hline $\mathrm{Mg}^{2+}$ & 0,9 & 0,5 & 0,6 & 0,6 & 0,6 & 0,5 \\
\hline $\mathrm{K}^{+}$ & 0,26 & 0,08 & 0,06 & 0,11 & 0,17 & 0,15 \\
\hline $\mathrm{Na}^{+}$ & 0,03 & 0,00 & 0,00 & 0,00 & 0,00 & 0,00 \\
\hline $\mathrm{Al}^{3+}$ & 0,0 & 0,0 & 0,0 & 0,0 & 0,0 & 0,0 \\
\hline $\mathrm{H}^{+}+\mathrm{Al}^{3+}$ & 3,4 & 2,4 & 1,6 & 1,3 & 1,2 & 1,3 \\
\hline SB & 7,7 & 3,7 & 2,5 & 2,2 & 1,8 & 1,7 \\
\hline $\mathrm{Ca}^{2+}+\mathrm{Mg}^{2+}$ & 7,4 & 3,6 & 2,5 & 2,1 & 1,6 & 1,5 \\
\hline CTC efetiva (t) & 7,69 & 3,71 & 2,54 & 2,16 & 1,81 & 1,68 \\
\hline CTC potencial(T) & 11,09 & 6,06 & 4,09 & 3,46 & 3,01 & 2,98 \\
\hline CTC (argila) & 187,90 & 93,12 & 41,51 & 24,61 & 15,46 & 14,48 \\
\hline \multicolumn{7}{|c|}{$\%$} \\
\hline V & 69 & 61 & 62 & 63 & 60 & 57 \\
\hline
\end{tabular}

passou a ser limitado a uma espessura $\geq 20 \mathrm{~cm}$ e os critérios diagnósticos do horizonte hydragric permanecem inalterados.

\section{TPA: processos e produtos}

Em geral, os solos do sítio arqueológico $\mathrm{BJ} 8$ são relativamente enriquecidos em $\mathrm{SiO}_{2}, \mathrm{TiO}_{2}$, e $\mathrm{MnO}$ (teores totais), $\mathrm{Cu}, \mathrm{Sc}, \mathrm{Ni}$ e $\mathrm{Zn}$ (teores traços) em relação ao UCC e PAAS. Enquanto que $\mathrm{MgO}, \mathrm{CaO}, \mathrm{Na}_{2} \mathrm{O}, \mathrm{K}_{2} \mathrm{O}$ e $\mathrm{P}_{2} \mathrm{O}_{5}$ (teores totais), $\mathrm{Ba}, \mathrm{Sr}, \mathrm{Cr}$ e $\mathrm{V}$ (teores traços) revelam empobrecimento elevado ( ). Estes perfis de concentração podem estar relacionados ao forte intemperismo do Grupo Itapecuru e outras feiçôes geológicas locais que contribuíram para o desenvolvimento dos solos do município de Bom Jesus do Tocantins.

Em comparação com os solos adjacentes (Figura 7), o solo TPA apresenta concentraçôes mais elevadas de $\mathrm{CaO}$, $\mathrm{P}_{2} \mathrm{O}_{5}$, C orgânico e $\mathrm{Zn}$ no horizonte superficial e $\mathrm{Na}_{2} \mathrm{O}, \mathrm{TiO}_{2}$ e $\mathrm{P}_{2} \mathrm{O}_{5}$ no subsuperficial, enquanto que as concentraçóes menores de $\mathrm{Fe}_{2} \mathrm{O}_{3}, \mathrm{MnO}$, Co, Ni e Cu ocorrem no horizonte superficial e $\mathrm{Fe}_{2} \mathrm{O}_{3}, \mathrm{MnO}, \mathrm{Co}, \mathrm{Ni}, \mathrm{Cu}, \mathrm{Zn}, \mathrm{Ba}$, Sr, Sc e Y no subsuperficial. Apesar destas diferenças, a similaridade entre as características morfológicas, mineralógicas e químicas dos

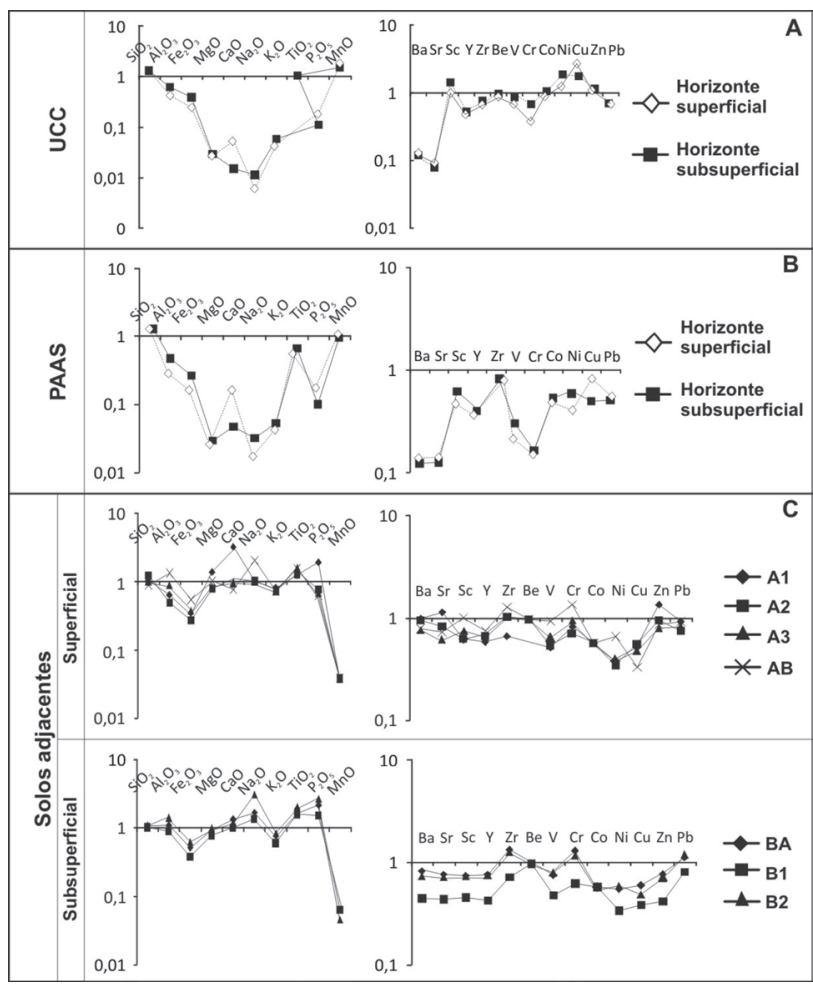

Figura 7-Concentrações dos elementos maiores, menores e traços do solo com Terra Preta Arqueológica (TPA) normalizados com: A) Crosta Continental Superior-UCC (Wedepohl 1995), B) Folhelhos Pós-Arqueanos Australianos - PAAS (Taylor e MacLennan 1985) e C) solos adjacentes do sítio BJ8. Valores maiores e menores que 1 indicam concentrações mais enriquecidas e empobrecidas, respectivamente, em comparação as referências descritas em A), B) e C). 
horizontes subsuperficiais do solo TPA e solos adjacentes sugerem que a TPA foi provavelmente desenvolvida a partir de Argissolos com posterior transformaçáo pedogenética através da introdução de materiais orgânicos e inorgânicos por uma colonização humana antiga, o que resultou no espessamento do horizonte superficial. Entretanto, esta influência antrópica antiga também resultou em modificações no horizonte subsuperficial, como as concentraçôes altas de $\mathrm{P}_{2} \mathrm{O}_{5}$ e principalmente $\mathrm{P}$ disponível. Esta tendência não foi observada nos Argissolos adjacentes e informações sobre fosfatos de alumínio não são conhecidas nas rochas da região (e.g. Nascimento e Góes 2007). Assim, os sistemas de classificação de solos como o Soil Taxonomy e SiBCS podem ser mais adequados para a identificação da TPA, uma vez que priorizam nas ordens do solo os processos pedogenéticos atuantes na formação e desenvolvimento do solo, relacionados com os horizontes subsuperficiais, além das transformaçôes pedogenéticas posteriores no horizonte superficial. Contudo, este trabalho recomenda a adição e revisão de alguns atributos diagnósticos como quantidade de artefatos cerâmicos e líticos, $\mathrm{P}_{2} \mathrm{O}_{5}, \mathrm{P}$ e Zn disponíveis, $\mathrm{C}$ orgânico, $\mathrm{Ca}^{2+}+\mathrm{Mg}^{2+}$, CTC e V no horizonte superficial do Soil Taxonomy e SiBCS para o agrupamento e distinção dos diversos tipos de solos antrópicos antigos da Amazônia.

\section{CONCLUSÕES}

A semelhança entre as características morfológicas, mineralógicas e químicas dos horizontes subsuperficiais do solo TPA e solos adjacentes sugerem que a TPA foi desenvolvida a partir dos Argissolos com posterior transformação pedogenética pela introdução de materiais orgânicos e inorgânicos por antigas colonizações humanas. Assim, o Soil Taxonomy e SiBCS podem ser mais adequados para a identificação da TPA, uma vez que priorizam na ordem do solo os processos pedogenéticos atuantes na formação e desenvolvimento do solo, relacionados aos horizontes subsuperficiais, além das transformaçôes pedogenéticas posteriores no horizonte superficial. Além disso, este trabalho recomenda a adição de alguns atributos diagnósticos como quantidade de artefatos cerâmicos e líticos, $\mathrm{P}_{2} \mathrm{O}_{5}$ (teor total), $\mathrm{P}$ e $\mathrm{Zn}$ disponíveis (teor disponível), $\mathrm{C}$ orgânico, $\mathrm{Ca}^{2+}+\mathrm{Mg}^{2+}$ (teor trocável), CTC e V no horizonte superficial do Soil Taxonomy e SiBCS, para o agrupamento e distinção dos diversos tipos de solos antrópicos antigos da Amazônia.

\section{AGRADECIMENTOS}

Ao CNPQ pelo apoio financeiro ao projeto "Assinaturas geoquímicas em terras pretas amazônicas e seu conteúdo cerâmico - AGTEPA, Processo: 484986/2007-4", a CAPES pela concessão da bolsa de mestrado, a Scientia Consultoria Científica pelo auxílio nas atividades de campo e aos membros dos laboratórios de Difração de Raios-X, Absorção Atômica,
Análises Químicas e Sedimentologia da UFPA/IG/PPGG pela colaboração nas análises laboratoriais.

\section{BIBLIOGRAFIA CITADA}

Costa, M.L.; Kern D.C. 1999. Geochemical signatures of tropical soils with archaeological black earth in the Amazon, Brazil. Journal of Geochemical Exploration, 66: 369-385.

Costa, M.L.; Kern, D.C.; Pinto, A.H.E.; Souza, J.R. da T. $2004 a$. The ceramic artifacts in Archaeological black earth (Terra Preta) from Lower Amazon Region, Brazil: mineralogy. Acta Amazonica, 34: 165-178.

Costa, M.L.; Kern, D.C.; Pinto, A.H.E.; Souza, J.R. da T. 2004 b. The ceramic artifacts in Archaeological black earth (Terra Preta) from Lower Amazon Region, Brazil: chemistry and geochemical evolution. Acta Amazonica, 34: 375-386.

Eden, M.J.; Bray, W.; Herrera, L.; Mcewan, C. 1984. "Terra Preta” soils and their archaeological context in the Caqueta basin of southeast Colombia. American Antiquity, 49: 125-140.

Embrapa. 2006. Sistema Brasileiro de Classificação de Solos. 2ed. Rio de Janeiro, Embrapa Solos. Centro Nacional de Pesquisa de solos. 306 pp.

FAO. 1998. World reference base for soil resources. Rome, Food and Agriculture Organization of the United Nations. World Soil Resource Report, 84. 109 pp.

FAO. 2007. World reference base for soil resources. Rome, Food and Agriculture Organization of the United Nations, World Soil Resource Report, 103. 145 pp.

Fisch, G.; Marengo, J.A.; Nobre, C.A. 1998. Uma Revisão Geral Sobre o Clima da Amazônia. Acta Amazonica, 28: 101-126.

Gong, Z.; Zhang, X.; Luo, G.; Shen, H., Spaargaren, O.C. 1997. Extractable phosphorus in soils with a fimic epipedon. Geoderma, 75: 289-296.

Gurjão, R.S.; Lemos, V.P.; Costa, M.L.; Dantas Filho, H.A.; Dantas, K.G.F.; Lima, W.T.S.; Kern, D.C. 2010. Comportamento do mercúrio em perfis de solos do sítio Ilha de Terra-Caxiuanã, Pará. Química Nova, 33: 821-826.

Kämpf, N.; Woods, W.I.; Sombroek, W.; Kern, D.C.; CUNHA, T.J.F. 2003. Classification of Amazonian Dark Earths and other ancient anthropic soils. p. 77-102. In: Lehmann, J.; Kern, D.C.; Glaser, B.; Woods, W.I. (Eds.). Amazonian Dark Earths. Origin, properties and management. Kluwer Academic Publishers, Dordrecht.

Kern, D.C.; Kämpf, N. 1989. Antigos assentamentos indígenas na formação de solos com terra preta arqueológica na regiáo de Oriximiná - Pará. Revista Brasileira de Ciências do Solo, 13: 219-225.

Kern D.C. 1996. Geoquímica e pedogeoquímica de Sítios Arqueológicos com Terra Preta na Floresta Nacional de Caxiuanã (Portel-Pará). Tese de Doutorado. Programa de Pós-Graduação em Geologia e Geoquímica, Universidade Federal do Pará. 119 pp.

Kern, D.C.; Costa, M.L. 1997. Os solos antrópicos. p. 105-119. In: Lisboa, P. (Ed.). Caxiuanã. Belém-PA, Museu Paraense Emílio Goeldi, Capítulo III. 
Kern, D.C.; D’Aquino, G.; Rodrigues, T.E.; Frazão, F.J.; Sombroek, W.; Myers, T.P.; Neves, E.G. 2003. p. 51-75. Distribution of Amazonian Dark Earths in the Brazilian Amazon. In: Lehmann, J.; Kern, D.C.; Glaser, B.; Woods, W.I. (Eds.). Amazonian Dark Earths. Origin, properties and management. Kluwer Academic Publishers, Dordrecht.

Kern, D.C.; Kämpf, N. 2005. Ação antrópica e pedogênese em solos com Terra Preta em Cachoeira-Porteira, Pará. Boletim do Museu Paraense Emílio Goeldi, 1:187-201.

Kilmer, V.J.; Alexander, L.T. 1949. Method of making mechanical analysis of soils. Soil Science, Baltimore, 68: 15-26.

Kim, J.S.; Sparovek, Gerd.; Longo, R.M.; De Melo, W.J.; Crowley, D. 2007. Bacterial diversity of terra preta and pristine forest soil from the Western Amazon. Soil Biology and Biochemistry, 39: 684-690.

Kretz, R. 1983. Symbols for rock-forming minerals. American Mineralogist, 68: 277-279.

Lehmann, J.; da Silva, Jr.J.P.; Steiner, C.; Nehls, T.; Zech, W.; Glaser, B. 2003. Nutrient availability and leaching in an archaeological anthrosol and a ferralsol of the Central Amazon basin: fertilizer, manure and charcoal amendments. Plant and Soil, 249: 343-357.

Lemos, R.C.; Santos, R.D. 2002. Manual de descrição e coleta de solo no campo. 4ed. Viçosa, MG. Sociedade Brasileira de Ciência do Solo. 83 pp.

Lemos, V.P.; Costa, M.L.; Gurjao, R.S.; Kern, D.C.; Mescouto, C.S.; dos Santos, W.T.L.; Valentim, T.L. 2009. Comportamento do Arsênio em perfis de solos do Sítio Ilha de Terra de Caxiuanã_ Pará. Revista Escola de Minas, 62: 39-146.

Lima, H.N. 2001. Gênese, química, mineralogia e micromorfologia de solos da Amazônia Ocidental. Tese de Doutorado. Pós-Graduação em Solos e Nutrição de Plantas, Universidade Federal de Viçosa. 176 pp.

Lima, H.N.; Schaefer, C.E.R.; Mello, J.W.V.; Gilkes, R.J.; Ker, J.C. 2002. Pedogenesis and pre-Columbian land use of "Terra Preta Anthrosols" (Indian black earth) of Western Amazonia. Geoderma, 110:1-17.

Major, J.; DiTommaso, A.; Lehmann, J.; Falcão, N.P.S. 2005. Weed dynamics on Amazonian Dark Earth and adjacent soils of Brazil. Agriculture, Ecosystems \& Environment, 111: 1-12.
Meireles A.R.O. 2004. Determinação de P, Ca, Mg, Cu, Mn e Zn em Terra Preta Arqueológica no sítio Ilha de Terra, região de Caxiuanã, Município de Melgaço-Pa. Dissertação de Mestrado. Programa de Pós-Graduação em Geologia e Geoquímica,Universidade Federal do Pará. 90 pp.

Nascimento, M.S.; Góes, A.M. 2007. Petrografia de arenitos e minerais pesados de depósitos cretáceos (Grupo Itapecuru), Bacia de São Luís-Grajaú, norte do Brasil. Revista Brasileira de Geociências, 37: 50-63.

Pabst, E. 1991. Critérios de distinção entre Terra Preta e Latossolo na região de Belterra e seus significados para a discussão pedogenética. Boletim do Museu Paraense Emílio Goeldi, 7: 5-19.

Sepof. 2008. Estatística Municipal de Bom Jesus do Tocantins. Secretaria de Estado de Planejamento, Orçamento e Finanças. 46 pp.

Smith, N.J. 1980. Anthrosols and human carrying capacity in Amazon. Annals of the Association of American Geographers, 70: 553-566.

Soil Survey Staff. 1993. Soil survey manual. Soil Conservation Service. U.S. Department of Agriculture Handbook 18.

Soil Survey Staff. 2010. Keys to Soil Taxonomy. USDA, Natural Resources Conservation Service. Washington-DC, 11 ed. 338 pp.

Sombroek, W.G.; Kern, D.C.; Rodrigues, T.; Cravo, M.S.; Cunha, T.J.; Woods, W.; Glaser, B. 2002. Terra Preta and Terra Mulata: pre-Columbian Amazon kitchen middens and agricultural fields, their sustainability and their replication. In: Dudal, R. (Ed.) Anthropogenic factors of soil formation, 17th World Congress of Soil Science. Bangkok: Transactions (CD-ROM).

Taylor, S.R.; Maclennan, S.M. 1985. The continental crust: its composition and evolution. Oxford, Blackwell. 312 pp.

Thorez, J. 1976. Practical identification of clay minerals. Bélgique, G. Lelotte. 90 pp.

Walkley, A. ; Black, I.A. 1934. An examination of the Degtjareff method for determining organic carbon in soils: Effect of variations in digestion conditions and of inorganic soil constituents. Soil Science 63:251-263.

Wedepohl, K.H. 1995. The composition of the continental crust. Geochemica et Cosmochimica Acta, 59:1277- 1232.

Recebido em: 23/07/2011

Aceito em: 30/12/2011 
